University of Nebraska - Lincoln

DigitalCommons@University of Nebraska - Lincoln

2015

\title{
Antecedent moisture and temperature conditions modulate the response of ecosystem respiration to elevated $\mathrm{CO}_{2}$ and warming
}

\author{
Edmund M. Ryan \\ Arizona State University \\ Kiona Ogle \\ Arizona State University \\ Tamara J. Zelikova \\ University of Wyoming, tzelikov@uwyo.edu \\ Dan R. Lecain \\ USDA-ARS, dan.lecain@ars.usda.gov \\ David G. Williams \\ University of Wyoming, dgw@uwyo.edu \\ See next page for additional authors
}

Follow this and additional works at: https://digitalcommons.unl.edu/usdaarsfacpub

Ryan, Edmund M.; Ogle, Kiona; Zelikova, Tamara J.; Lecain, Dan R.; Williams, David G.; Morgan, Jack A.; and Pendall, Elise, "Antecedent moisture and temperature conditions modulate the response of ecosystem respiration to elevated $\mathrm{CO}_{2}$ and warming" (2015). Publications from USDA-ARS / UNL Faculty. 1613.

https://digitalcommons.unl.edu/usdaarsfacpub/1613

This Article is brought to you for free and open access by the U.S. Department of Agriculture: Agricultural Research Service, Lincoln, Nebraska at DigitalCommons@University of Nebraska - Lincoln. It has been accepted for inclusion in Publications from USDA-ARS / UNL Faculty by an authorized administrator of DigitalCommons@University of Nebraska - Lincoln. 


\section{Authors}

Edmund M. Ryan, Kiona Ogle, Tamara J. Zelikova, Dan R. Lecain, David G. Williams, Jack A. Morgan, and Elise Pendall 


\title{
Antecedent moisture and temperature conditions modulate the response of ecosystem respiration to elevated $\mathrm{CO}_{2}$ and warming
}

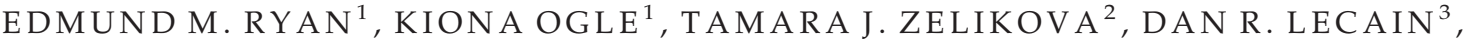 \\ DAVID G. WILLIAMS ${ }^{2}$, JACK A. MORGAN ${ }^{3}$ and ELISE PENDALL ${ }^{2,4}$ \\ ${ }^{1}$ School of Life Sciences, Arizona State University, Tempe, AZ, USA, ${ }^{2}$ Department of Botany, University of Wyoming, Laramie, \\ WY, USA, ${ }^{3}$ USDA-ARS, Fort Collins, CO, USA, ${ }^{4}$ Hawkesbury Institute for the Environment, University of Western Sydney, \\ Penrith, NSW, Australia
}

\begin{abstract}
Terrestrial plant and soil respiration, or ecosystem respiration $\left(\mathrm{R}_{\mathrm{eco}}\right)$, represents a major $\mathrm{CO}_{2}$ flux in the global carbon cycle. However, there is disagreement in how $\mathrm{R}_{\text {eco }}$ will respond to future global changes, such as elevated atmosphere $\mathrm{CO}_{2}$ and warming. To address this, we synthesized six years (2007-2012) of $R_{\text {eco }}$ data from the Prairie Heating And $\mathrm{CO}_{2}$ Enrichment (PHACE) experiment. We applied a semi-mechanistic temperature-response model to simultaneously evaluate the response of $\mathrm{R}_{\text {eco }}$ to three treatment factors (elevated $\mathrm{CO}_{2}$, warming, and soil water manipulation) and their interactions with antecedent soil conditions [e.g., past soil water content (SWC) and temperature (SoilT)] and aboveground factors (e.g., vapor pressure deficit, photosynthetically active radiation, vegetation greenness). The model fits the observed $R_{\text {eco }}$ well $\left(R^{2}=0.77\right)$. We applied the model to estimate annual (March-October) $R_{\text {eco, }}$ which was stimulated under elevated $\mathrm{CO}_{2}$ in most years, likely due to the indirect effect of elevated $\mathrm{CO}_{2}$ on $\mathrm{SWC}_{\text {. When }}$ aggregated from 2007 to 2012, total six-year $\mathrm{R}_{\text {eco }}$ was stimulated by elevated $\mathrm{CO}_{2}$ singly (24\%) or in combination with warming (28\%). Warming had little effect on annual $\mathrm{R}_{\mathrm{eco}}$ under ambient $\mathrm{CO}_{2}$, but stimulated it under elevated $\mathrm{CO}_{2}$ (32\% across all years) when precipitation was high (e.g., 44\% in 2009, a 'wet' year). Treatment-level differences in $\mathrm{R}_{\mathrm{eco}}$ can be partly attributed to the effects of antecedent SoilT and vegetation greenness on the apparent temperature sensitivity of $R_{\text {eco }}$ and to the effects of antecedent and current SWC and vegetation activity (greenness modulated by VPD) on $\mathrm{R}_{\text {eco }}$ base rates. Thus, this study indicates that the incorporation of both antecedent environmental conditions and aboveground vegetation activity are critical to predicting $\mathrm{R}_{\text {eco }}$ at multiple timescales (subdaily to annual) and under a future climate of elevated $\mathrm{CO}_{2}$ and warming.
\end{abstract}

Keywords: antecedent effects, carbon cycle, elevated $\mathrm{CO}_{2}$, grasslands, soil respiration, temperature acclimation, warming

Received 11 August 2014; revised version received 17 December 2014 and accepted 25 January 2015

\section{Introduction}

Terrestrial plant and soil respiration, or ecosystem respiration (hereafter, $\mathrm{R}_{\text {eco }}$ ), represents a major $\mathrm{CO}_{2}$ flux in the global carbon cycle. Plant, root, and microbial respiration together account for approximately 118.7 Gt $C \mathrm{yr}^{-1}$, which is $\sim 95 \%$ of the carbon that is assimilated through photosynthesis (Roy et al., 2001; Friedlingstein et al., 2006; Canadell et al., 2007; Beer et al., 2010; Harmon et al., 2011; Arora et al., 2013). Although ecosystem respiration is a major component of the global carbon cycle, the effects of elevated atmosphere $\mathrm{CO}_{2}$ and warming on $\mathrm{R}_{\text {eco }}$ remain uncertain. In particular, soil respiration accounts for $\sim 90 \%$ of $R_{\text {eco }}$ in temperate grasslands, and the influence of global change on

Correspondence: Edmund M. Ryan, tel. 480727 3731, fax 480965 6899, e-mail: emryan2@asu.edu

For submission to: Global Change Biology this component of the global carbon budget is poorly constrained (Xiao et al., 2003; Pendall et al., 2004; Williams et al., 2005; Hui et al., 2008). Thus, global change experiments provide critical data to help constrain predictions of future changes in soil and ecosystem respiration, both of which are expected to have a large impact on the medium- to long-term carbon sequestration potential of the terrestrial biosphere.

The effect of warming on soil and ecosystem respiration is difficult to predict (Cox et al., 2000; Davidson et al., 2006), and the results from warming studies are often contradictory and vary according to biome and latitude. For example, a meta-analysis of 306 studies conducted between 1989 and 2008 found that soil respiration was generally positively correlated with increasing air temperature, although there was much variation in the strength of this relationship (Bond-Lamberty \& Thomson, 2010). Conversely, a different meta-analysis found no consistent effects of temperature on soil 
respiration across 17 experimental warming studies, and in three grassland sites, factors other than warming explained differences in soil respiration (Rustad et al., 2001). Other factors that drove soil respiration responses to warming included changes in growing season length, enhanced nutrient availability, shifts in species composition, and altered soil water, many of which are generally not accounted for in terrestrial carbon cycle models (Luo, 2007).

In contrast to the inconsistent effects of warming, elevated $\mathrm{CO}_{2}$ has been shown to stimulate various compo-

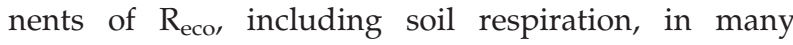
ecosystems (Dieleman et al., 2012). For example, in a deciduous temperate forest in eastern Tennessee, USA, elevated $\mathrm{CO}_{2}$ stimulated heterotrophic respiration (by $10 \%$ over three years) and total soil respiration (nearly $40 \%$ over 1.5 years) in a FACE (Free Air and $\mathrm{CO}_{2}$ Enrichment) study and an open-top chamber experiment (Norby et al., 2002; Wan et al., 2007), respectively. Elevated $\mathrm{CO}_{2}$ also simulated soil respiration (by $20 \%$ over seven years) at a pine forest FACE site in North Carolina, USA (Bernhardt et al., 2006). Similarly, in a semiarid Colorado grassland, soil respiration increased under elevated $\mathrm{CO}_{2}$ by $\sim 25 \%$ in a wet year and $\sim 85 \%$ in a dry year (Pendall et al., 2003). This $\mathrm{CO}_{2}$ stimulation effect has been attributed to enhanced decomposition following increased substrate availability and soil moisture, increasing both autotrophic and heterotrophic components of soil respiration (Adair et al., 2011; Pendall et al., 2013).

Terrestrial ecosystem models require accurate representations of the interacting effects of climate change, yet the coupled belowground-aboveground responses underlying $R_{\text {eco }}$ are poorly documented. Applying the ORCHIDEE model to data from 108 sites over a 20-year period, Piao et al. (2008) found that warming had a large positive effect on $R_{\text {eco }}$ in the autumn and a small positive effect in the spring at northern high latitudes. The effects of warming, however, can be mediated by precipitation, with profound effects on terrestrial carbon fluxes. For example, Ciais et al. (2005) found that $R_{\text {eco }}$ decreased by $77 \mathrm{gC} \mathrm{m}^{-2} \mathrm{yr}^{-1}(\sim 12 \%)$ across Europe as a result of rainfall deficit and extreme summer heat during the European heat wave of 2003. This decrease in $R_{\text {eco }}$ was attributed to reductions in gross primary production and heterotrophic respiration, both of which were primarily driven by reductions in soil water content.

To accurately describe and predict the effects of climate change on $R_{\text {ecor }}$ models should incorporate aboveground processes and antecedent factors as drivers of belowground responses (Reichstein et al., 2003; Högberg \& Read, 2006; Bardgett, 2011). For instance, shading and tree girdling experiments demonstrate the importance of photosynthesis drivers (e.g., light) for soil respiration (Craine et al., 1999; Högberg et al., 2001; Högberg \& Read, 2006). Moreover, $R_{\text {eco }}$ is very responsive to the effects of past conditions, such as antecedent soil water content or lagged precipitation (Huxman et al., 2004; Xu et al., 2004; Harper et al., 2005; Chou et al., 2008; Dezi, 2011; Oikawa et al., 2014). For example, soil respiration was enhanced following a rain event, especially if the previous week or month was dry (Xu et al., 2004; Cable et al., 2008; Barron-Gafford et al., 2014). These antecedent effects, however, can vary across diurnal, weekly, and monthly timescales (Vargas et al., 2011; Cable et al., 2013). In general, above- and/or belowground antecedent environmental conditions can explain spatial variation in soil respiration or $\mathrm{R}_{\text {eco }}$ (Barron-Gafford et al., 2014; Oikawa et al., 2014) and are likely to interact with elevated $\mathrm{CO}_{2}$ and warming (Polley et al., 2013).

Many studies have documented the singular effects of elevated $\mathrm{CO}_{2}$ and warming (Rustad et al., 2001; Norby \& Zak, 2011), but these factors are expected to interact to affect $R_{\text {eco, }}$ and the outcome of those interactions is unclear (Pendall et al., 2004). Multifactor experiments that evaluate combined effects of elevated $\mathrm{CO}_{2}$ and warming on soil and ecosystem respiration in natural ecosystems are rare, especially over longer timescales (Dieleman et al., 2012). We addressed this knowledge gap by asking the following questions: (i) What are the consequences of warming, elevated $\mathrm{CO}_{2}$, and altered soil moisture for $R_{\text {eco }}$ over annual and multiyear timescales? (ii) How important are current and antecedent environmental factors (e.g., soil water and soil temperature) for understanding variation in $\mathrm{R}_{\text {eco }}$ and its long-term response to warming and elevated $\mathrm{CO}_{2}$ ? Likewise, (iii) how important are aboveground factors (e.g., indices of plant activity) for predicting variation in $R_{\text {eco }}$ and its response to warming and elevated $\mathrm{CO}_{2}$ ?

To rigorously address our research questions, we conducted a unique analysis involving six years of $R_{\text {eco }}$ data and associated below- and aboveground covariates generated from a multifactor global change experiment conducted in a mixed-grass prairie in Wyoming. We employed a novel Bayesian statistical analysis that analyzed these data in the context of a semi-mechanistic model, and which simultaneously quantified the potential impacts of elevated $\mathrm{CO}_{2}$ and warming on the base rate (i.e., $R_{\text {eco }}$ at a given temperature) and the apparent temperature sensitivity of $R_{\text {eco. }}$. The model structure also allowed us to explore how $\mathrm{CO}_{2}$ and warming interacted with antecedent soil water, antecedent temperature, and aboveground indices of vegetation activity to affect $R_{\text {eco }}$ and its component 
responses. Moreover, the hierarchical Bayesian framework was constructed to accommodate the experimental design, to allow for a rigorous quantification of the antecedent effects, and to propagate uncertainty in our model and parameter estimates to obtain realistic estimates of annual $\mathrm{CO}_{2}$ efflux.

\section{Materials and methods}

\section{Site description}

The Prairie Heating and $\mathrm{CO}_{2}$ Enrichment experiment is located in a temperate, mixed-grass prairie near Cheyenne, Wyoming (elevation $=1930 \mathrm{~m}$ ). The site has a semiarid climate, characterized by moderately long winters and relatively warm summers. Mean monthly temperature varies from $-2.5{ }^{\circ} \mathrm{C}$ in January to $17.5^{\circ} \mathrm{C}$ in July, and mean annual precipitation is $384 \mathrm{~mm}$ (Morgan et al., 2011). Over 75\% of the vegetation cover consists of the $\mathrm{C}_{3}$ grasses western wheatgrass (Pascopyrum smithii (Rydb.) A. Löve) and needle-and-thread grass (Hesperostipa comata Trin and Rupr), and the $C_{4}$ perennial grass blue grama (Bouteloua gracilis (H.B.K.) Lag). The soil is a fine-loamy, mixed, mesic Aridic Argiustoll, and biological crusts are not present (Bachman et al., 2010).

\section{Experimental design}

The PHACE experiment involves an incomplete factorial design with 30 plots randomly assigned to six treatments, with five plots per treatment level (Parton et al., 2007). The circular plots (3.4 $\mathrm{m}$ diameter) are separated from surrounding soil by a plastic flange buried to a depth of $60 \mathrm{~cm}$ (Bachman et al., 2010). The six treatments - denoted as ct, cT, Ct, CT, ct-d, and ct-s - involve different combinations of atmospheric $\mathrm{CO}_{2}$ [ambient at 380-400 ppm (denoted as ' $\mathrm{c}$ ') vs. elevated at $600 \mathrm{ppm}\left({ }^{\prime} \mathrm{C}^{\prime}\right)$ ], temperature [ambient/not heated (' $\mathrm{t}$ ') vs. heated by 1.5 (day) or 3.0 (night) ${ }^{\circ} \mathrm{C}\left({ }^{\prime} \mathrm{T}^{\prime}\right)$ ], and watering [none vs. shallow ('s') or deep ('d') irrigation, which are only applied under ambient $\mathrm{CO}_{2}$ and temperature ('ct')]. The goal of the irrigation treatments was to increase soil moisture to approximately match that of the Ct plots by irrigating when soil moisture fell below $85 \%$ of $\mathrm{Ct}$ at $5-25 \mathrm{~cm}$ depth. In 2007, the shallow irrigation plots received an equivalent of $18 \mathrm{~mm}$ of precipitation on 5 irrigation dates in 2007, the equivalent of $90 \mathrm{~mm}$ of additional growing season precipitation. From 2008 to 2011, irrigated plots received an equivalent of $21 \mathrm{~mm}$ of precipitation three times during the growing season (equivalent to $63 \mathrm{~mm}$ of additional precipitation), and in 2012, $65 \mathrm{~mm}$ of water was added four times during the growing season (equivalent to $260 \mathrm{~mm}$ ). The ct-d plots were irrigated with the same total amount as the ct-s plots received the previous summer, but applied in fall and spring. Free Air $\mathrm{CO}_{2}$ Enrichment (FACE) technology (Miglietta et al., 2001) was used to raise atmospheric $\mathrm{CO}_{2}$ to $600 \mathrm{ppm}$ in the $\mathrm{Ct}$ and $\mathrm{CT}$ plots. A ceramic heater system using a proportional-integral-derivative (PID) feedback loop (Kimball, 2005) was used to raise temperatures in the $\mathrm{CT}$ and $\mathrm{CT}$ plots.

\section{Data description}

All data were measured in the field from 2007 to 2012 and consisted of $R_{\text {eco }}\left(\mu \mathrm{mol} \mathrm{m} \mathrm{m}^{-1}\right)$, associated soil temperature (SoilT), volumetric soil water content (SWC), and aboveground factors consisting of ecosystem phenology ('greenness'), photosynthetically active radiation (PAR), air temperature, and relative humidity. One $\mathrm{R}_{\text {eco }}$ chamber frame was established in each plot, and $R_{\text {eco }}$ was measured on 96 days over six growing seasons, each spanning the period between May and September. Measurement days were typically separated by 2-4 weeks; approximately every 6 weeks, $R_{\text {eco }}$ was measured using a canopy gas exchange chamber (Jasoni et al., 2005; Bachman et al., 2010) five times during the day in each plot (nominal times $=04: 00,09: 00,12: 00,16: 00$ and 21:00); otherwise, a single plot-level measurement was made at midday. Soil thermocouples were installed at depths of 3 and $10 \mathrm{~cm}$ to record hourly SoilT (type-T thermocouples). SWC was measured at a depth of 5-15 cm on an hourly basis (EnviroSMART probe; Sentek Sensor Technologies, Stepney, Australia), but daily averages were computed for this analysis because, with the exception of days receiving precipitation, SWC showed little diurnal variation, and $R_{\text {eco }}$ measurements were not made around precipitation events. A weather station at the site recorded air temperature, relative humidity, and PAR. Vegetation greenness was quantified every 2-4 weeks between March and October, resulting in 71 separate greenness measurement days spanning 2007-2012; photographs were taken for all 30 plots on each measurement day using a 2-m-high camera stand and a $1-\mathrm{m}^{2}$ ground frame. SAMPLEPOINT software (Booth et al., 2006, www.samplepoint.org) was used to quantify parts of the photograph that were not vegetation (i.e., soil or litter) and to classify the different species of grass. Greenness (Gness) was quantified by converting the image pixels within each photograph to a matrix of numbers using MATLAB R2011a and quantifying the hue, saturation, and value scales for the detection of green. It varies from 0 (absence of green biomass) to 1 (plot is completely covered with green biomass). See Zelikova et al. (accepted) for full details on how greenness was quantified.

\section{Gap-filling of environmental data}

The SWC, SoilT, and micrometeorological data had occasional missing time periods or days due to instrument failure $(<1 \%$, $6 \%$, and $2.5 \%$ for the micrometeorological, SWC, and SoilT data, respectively). We primarily used data from a nearby plot of the same treatment to gap-fill soil moisture and temperature, and cubic spline interpolation was used to gap-fill the missing micrometeorological data. Since the dates when repeat plot photographs were taken for vegetation greenness did not coincide with days when $R_{\text {eco }}$ was measured, linear interpolation was employed to estimate greenness on $R_{\text {eco }}$ measurement days. See Appendix S1 for full details of these gap-filling procedures.

\section{Data synthesis and modeling}

We synthesized the $\mathrm{R}_{\text {eco }}$ data in the context of a nonlinear mixed effects model that allowed us to quantify how the 
experimental treatments influenced $\mathrm{R}_{\mathrm{eco}}$, and how they interacted with current and antecedent SoilT, SWC, and aboveground factors (e.g., vegetation greenness) to affect different properties of the $R_{\text {eco }}$ response. Given the distributional properties of the observed $R_{\text {eco }}$ data (i.e., $R_{\text {eco }}>0$ and variance often increased with mean) and previous studies (Cable et al., 2008 , 2011, 2013), we assumed that the observed $R_{\text {eco }}$ data $\left(\mathrm{R}_{\text {eco }}{ }^{\text {obs }}\right)$ follow a log-normal distribution such that for treatment $t(t=1, \ldots, 6)$ and measurement time $i\left[i=1, \ldots, \mathrm{N}_{t}\right.$, where $\mathrm{N}_{t}$ is the number of observations for treatment $t$, which varied from $531(\mathrm{Ct})$ to $659(\mathrm{ct}-\mathrm{d})]$ :

$$
\log \left(\mathrm{R}_{\mathrm{eco}_{i, t}}^{\mathrm{obs}}\right) \sim \operatorname{Normal}\left(\mu \mathrm{LR}_{i, t}, \sigma_{\mathrm{LR}}^{2}\right)
$$

where $\mu \mathrm{LR}$ is the mean or predicted $\log \left(\mathrm{R}_{\mathrm{eco}}\right)$ and $\sigma_{\mathrm{LR}}^{2}$ represents the observation variance.

Note that time $i$ represents a specific day $(d)$ and hour $(h)$ of the experiment for convenience, except when it is necessary to explicitly specify the corresponding day and hour.

We employ a semi-mechanistic, nonlinear process model for $\mu \mathrm{LR}$ that is a modification of an Arrhenius-type temperature function (Lloyd \& Taylor, 1994). On the log scale, $\mu \mathrm{LR}$ is

$$
\mu \mathrm{LR}_{i, t}=\mathrm{LRb}_{i, t}+E_{o_{i, t}}\left(\frac{1}{283.15-T_{o_{t}}}-\frac{1}{\operatorname{SoilT}_{i, p}-T_{o_{t}}}\right)
$$

where $R_{\text {base }_{i, t}}=\exp \left(\mathrm{LRb}_{i, t}\right)$ is the base respiration rate at $10{ }^{\circ} \mathrm{C}$ (283.15 Kelvin), $E_{o}$ is analogous to an energy of activation, but when Eqn (2) is applied to field observations of $\mathrm{R}_{\text {eco, }} E_{o}$ provides an index of the apparent temperature sensitivity of $R_{\text {eco }}$ (Davidson \& Janssens, 2006; Sierra, 2012). The interpretation of $T_{o}$ is less straightforward, but it is also related to apparent temperature sensitivity, and we allow $T_{o}$ to vary by treatment level. Soil temperature was measured at two depths ( 3 and $10 \mathrm{~cm}$ ), and SoilT was estimated as a weighted average of each depth's temperature, with $\mathrm{w}_{t}$ and $\left(1-w_{t}\right)$ representing the treatment-specific relative importance (weight) of the 3 and $10 \mathrm{~cm}$ depths, respectively; $w_{t}$ is a parameter to be estimated.

We specify linear mixed effects models for $\mathrm{R}_{\text {base }_{i, t}}$ and $E_{o_{i, t}}$ to incorporate the potential influence of current and antecedent soil and aboveground drivers on these two components of the $\mathrm{R}_{\text {eco }}$ response. For example, antecedent SWC $\left(\mathrm{SWC}_{\mathrm{ant}}\right)$ has been found to significantly affect soil respiration in arid systems (Cable et al., 2008, 2013; Barron-Gafford et al., 2014), and the inclusion of antecedent soil temperature $\left(S_{\text {Soil }} \mathrm{T}_{\text {ant }}\right)$ allows for the apparent temperature sensitivity $\left(E_{o}\right)$ to acclimate to prevailing temperature conditions (Luo et al., 2001). The importance of including aboveground (ABG) factors for predicting $\mathrm{R}_{\text {eco }}$ and/or $E_{o}$ has been highlighted in several places (Reichstein et al., 2003; Högberg \& Read, 2006; Bardgett, 2011), in particular, PAR (Craine et al., 1999), vapor pressure deficit (VPD) (Carbone et al., 2008; Cable et al., 2013), indices of vegetation activity or greenness (Pendall et al., 2001; Cable et al., 2012), and photosynthetic activity (Drake et al., 2011; BarronGafford et al., 2014). We did not measure photosynthesis on the $R_{\text {eco }}$ measurement days, but we incorporated proxies of aboveground plant activity in two ways: (i) A main effect of vegetation greenness (Gness) was included such that above- ground activity was assumed to be proportional to Gness, and (ii) interactions between Gness, VPD, and PAR were included, reflecting potential controls of these environmental factors on photosynthesis. Thus, $E_{o}$ is given by

$$
\begin{aligned}
E_{o_{i, t}}= & \alpha_{0, t}+\alpha_{1, t} \mathrm{SWC}_{i, t}+\alpha_{2, t} \mathrm{SWC}_{\mathrm{ant}_{i, t}}+\alpha_{3, t} \mathrm{SWC}_{i, t} \times \mathrm{SWC}_{\mathrm{ant}_{i, t}} \\
& +\alpha_{4, t} \mathrm{SoilT}_{\mathrm{ant}_{i, t}}+\mathrm{ABG}_{i, t}+\epsilon_{\mathrm{plot}}
\end{aligned}
$$

$\mathrm{ABG}_{i, t}=\left(\alpha_{5, t} \mathrm{PAR}_{\mathrm{ant}_{i, t}}+\alpha_{6, t} \mathrm{VPD}_{\mathrm{ant}_{i, t}}+\alpha_{7, t} \mathrm{PAR}_{\mathrm{ant}_{i, t}} \times \mathrm{VPD}_{\mathrm{ant}_{i, t}}\right)$ $\times$ Gness $_{i, t}+\alpha_{8, t}$ Gness $_{i, t}$

where $\varepsilon_{\text {plot }}$ represents a plot random effect. The expression for $\mathrm{LRb}_{i, t}$ is the same as that of $E_{o_{i, t}}$, except that there is no Soil $T_{\mathrm{ant}_{\mathrm{i}, \mathrm{t}}}$ term, and it has its own set of parameters, labeled $\beta_{0}, \ldots, \beta_{7}$, with $\beta_{4}-\beta_{7}$ corresponding to the aboveground effects in Eqn (4).

\section{Quantification of antecedent drivers}

We employ a novel stochastic modeling approach (Ogle et al., 2015) to define the antecedent driving variables, as adopted by Cable et al. (2013) and Barron-Gafford et al. (2014). This new approach differs from a more 'standard' approach that computes the antecedent variables prior to the data analysis, often by averaging the daily or hourly variables over a specified time period. Here, we allow the $\mathrm{R}_{\text {eco }}$ data to determine the relative importance of each variable at different past time periods. Based on exploratory analyses, and following Cable et al. (2013), we assumed that $R_{\text {eco }}$ was influenced by SoilT and the aboveground covariates over daily timescales and by SWC over weekly timescales that integrate over past precipitation events. Thus, $\mathrm{VPD}_{\text {ant }}, \mathrm{PAR}_{\text {ant }}$, and SoilT $\mathrm{T}_{\text {ant }}$ were modeled as weighted averages of the corresponding observed daily values over the past seven days; likewise, $\mathrm{SWC}_{\mathrm{ant}}$ was modeled as a weighted average of the observed weekly SWC over the past 10 weeks. Let $X$ denotes one of the daily timescale variables ( $X=$ VPD, PAR, or SoilT); we first computed the 24-h means for each variable $(\bar{X})$ based on the observed hourly values. The antecedent variable $\left(X_{\mathrm{ant}}\right)$ is expressed as a weighted average of the past daily mean values such that for an $R_{\text {eco }}$ observation made on plot $p$ and at time $i$ :

$$
X_{\text {ant }_{\mathrm{i}, \mathrm{p}}}=\sum_{k=1}^{\text {Nperiods }} W_{X_{k, p}} \bar{X}_{t p(i)-k, p}
$$

where $t p(i)$ represents the 24-h time period associated with $\mathrm{R}_{\text {eco }}$ observation $i$. For example, if an observation of $\mathrm{R}_{\text {eco }}$ was made at 9:00 am on day 10, then the associated t $p$ covers 9:00 am on day 9 to 9:00 am on day 10; $k=1$ refers to the previous 24-h time period (e.g., 9:00 am day 8 to 9:00 am day 9), and similar for $k=2,3, \ldots, \mathrm{N}_{\text {periods. }} \mathrm{VPD}_{\text {ant }}$ and $\mathrm{PAR}_{\text {ant }}$ are not indexed by $p$ as these data are site specific rather than plot specific. We do not specify the values for the weights $\left(W_{X}\right)$ as they are parameters to be estimated. The formula for $\mathrm{SWC}_{\mathrm{ant}}$ is similar to Eqn (5) except that the time period $(k=1, \ldots$, $\mathrm{N}_{\text {periods }}$ ) is on the weekly scale. To reduce the number of weights associated with $\mathrm{SWC}_{\mathrm{ant}}$, we assigned individual weights to each of the first four weeks into the past, the fifth 
weight to past weeks 5 and 6 , and the sixth weight to past weeks $7-10$.

\section{Bayesian framework and prior distributions}

The above model is nonlinear because it is based on the Arrhenius-type temperature-response function, with mixed effects associated with the plot random effects and fixed effects for the different treatment levels and for the continuous environmental and aboveground covariates. We fit this model via a hierarchical Bayesian framework to accommodate the nonlinear model and the experimental design, and to explicitly estimate sources of variability due to observation error, model or process error, and parameter uncertainty (Clark, 2003; Ogle \& Barber, 2008; Cressie et al., 2009; Parslow et al., 2013). This approach produces posterior distributions for all stochastic quantities of interest, and we summarize their marginal posteriors by reporting posterior means, 95\% credible intervals (CIs), and Bayesian P-values (Gelman et al., 2003).

The Bayesian approach also allows us to incorporate prior information. For example, based on the extensive synthesis conducted by Lloyd \& Taylor (1994) on the response of soil respiration to temperature, we constructed semi-informative priors for $\alpha_{0}$ [base rate parameter of $E_{o}$ in Eqn (3)] and $T_{o}$ [Eqn (2)]. Specifically, we assumed $\alpha_{0, t} \sim \operatorname{Normal}(308.56,1000)$ and $T_{o} \sim \operatorname{Normal}(227.13,1000)$. Lloyd \& Taylor (1994) also state that $T_{o}$ can only lie between $0 \mathrm{~K}$ and the minimum observed SoilT; thus, the Normal prior for $T_{o}$ was also truncated to the interval [0,261]. With no specific information on the parameters $\alpha_{1}-\alpha_{8}$ and $\beta_{0}-\beta_{7}$ in Eqns (3) and (4), independent and diffuse Normal distributions were used as priors for each. The plot-level random effects $\left[\varepsilon^{\prime}\right.$ s, Eqn (3)] for the $E_{o}$ and LRb functions were assigned normal priors with a zero mean and variances given by $\sigma_{1}^{2}$ and $\sigma_{2}^{2}$ for $E_{o}$ and LRb, respectively. Uniform priors were assigned to the standard deviations, including that associated with the observation error in Eqn (1), such that $\sigma_{k} \sim \mathrm{U}(0,150)(k=1,2)$ and $\sigma_{\mathrm{LR}} \sim \mathrm{U}(0,10)$. Dirichlet priors were used for the vectors of antecedent weights in Eqn (5), thus obeying the constraint that the $W_{X}$ 's must sum to one across past time periods $\left(k=1, \ldots, \mathrm{N}_{\text {periods }}\right)$ and ensuring that $0 \leq W_{X k} \leq 1$ for all variables $X$, treatment levels $t$, and times into the past $k$.

\section{Alternative model formulations}

We refer to the above model as the 'main' model. Two other models were implemented evaluate the importance of including antecedent and/or aboveground effects. The first alternative model did not include any of the aboveground covariates [i.e., the ABG term was excluded in Eqn (3)], while the other model did not include any antecedent covariates [i.e., all terms with a subscript 'ant' in Eqns (3) and (4) were removed]. A fourth model that included an extra term in Eqn (2) to account for day random effects, in addition to plot random effects, was also considered. As the predicted day random effects showed no temporal structure, this model was not included in our final analysis.

\section{Model implementation and assessment}

We used the software package OPENBUGs (Lunn et al., 2009) to implement the Bayesian analysis of the main model and the three model variants. OPENBUGS uses Markov chain Monte Carlo (MCMC) techniques to sample from the joint posterior of the model parameters, and we ran three parallel chains for each model. Depending on the model, the number of iterations per chain varied from 50000 to 550000 , with the first 1000-50 000 iterations discarded as burn-in, and the amount of thinning ranged from every 10th to 500th iteration to sufficiently reduce autocorrelation in the chains and to reduce storage requirements. This produced 3000 independent samples from the posterior distribution for each parameter, for each model. Convergence was assessed using the built-in BrooksGelman-Rubin diagnostic tool (Gelman et al., 2003).

We assessed the ability of each model to fit the observed $R_{\text {eco }}$ data by plotting observed vs. predicted $R_{\text {eco }}$ values. The coefficient of determination $\left(R^{2}\right)$ and the coefficients of the corresponding regression line give an informal evaluation of replicative performance (i.e., 'goodness of fit'). We also computed posterior predictive loss $(D)$, a model comparison statistic, which is the sum of a goodness-of-fit term $(G)$ and a model complexity penalty term $(P)$ (Gelfand \& Ghosh, 1998). One model is more desirable over another if it has a lower $D$ value, which can result from a lower $G$ value (better fit) and/or a lower $P$ value (less complex).

\section{Estimates of annual $R_{\text {eco }}$}

We used the posterior results from the main model to obtain hourly estimates of $R_{\text {eco }}$ for each treatment level. This was accomplished by sampling model parameters from their joint posterior distribution and computing hourly, treatment-level $\mathrm{R}_{\text {eco }}$ based on Eqns (2)-(5), with $\varepsilon_{\text {plot }}=0$, and given hourly observations of the covariates (i.e., SWC, SoilT, Gness, VPD, PAR). These hourly values were summed to obtain posterior predictive distributions of treatment-level daily and annual (March-October) $R_{\text {eco. }}$ The annual estimates were also summed to obtain predicted annual $R_{\text {eco }}$ over the six-year study period.

Moreover, the majority of models do not include antecedent variables in $\mathrm{R}_{\text {eco }}$. To quantify the effect of ignoring antecedent conditions, we also computed annual and 6-year $R_{\text {eco }}$ sums based on the model lacking antecedent effects [i.e., only had current SWC and Gness as covariates in Eqns (3) and (4)] and compared these estimates to those obtained from the main model (above)

\section{Results}

\section{Assessment of model performance}

The main model accurately predicted ecosystem respiration $\left(R_{\text {eco }}\right)$ over the entire set of observations $\left(R^{2}=0.77\right)$. However, the goodness of fit varied among the treatments, with $\mathrm{R}^{2}$ ranging from $0.84(\mathrm{cT})$ and 0.79 (ct) to 0.63 (CT) (Fig. 1). The treatment-level differences 
in model fit are also illustrated in time series plots of observed vs. predicted $\log \left(\mathrm{R}_{\text {eco }}\right)$ (see Fig. 2 for 2009 and Fig. S1a-e for remaining years). For any year, $<5 \%$ of the observations fell outside of the predicted $95 \%$ credible intervals, and at least three quarters of these were underpredicted by the model, with the majority occurring between June and August. The inclusion of the aboveground and antecedent covariates was important for predicting $R_{\mathrm{eco}}$ and exclusion of either notably reduced model fit $\left(R^{2}=0.68\right.$ and 0.64 , respectively) and increased posterior predictive loss. The likely reasons for the variations in model performance among treatments are discussed in the Appendix S2).

\section{Treatment effects on $R_{\text {eco }}$}

We assessed treatment effects on annual (March-October) ecosystem respiration values (Fig. 3). Elevated $\mathrm{CO}_{2}$ increased annual ecosystem respiration $\left(\mathrm{R}_{\text {eco; }}\right.$; Fig. 3; ct vs. Ct or cT vs. CT, Bayesian $P<0.05$ in 2008,
2009, 2011 and 2012, $P<0.10$ in 2007 and 2010). The combination of warming and elevated $\mathrm{CO}_{2}$ stimulated $\mathrm{R}_{\text {eco }}$ compared to the control (Fig. 3) when aggregated over the six years (2007-2012, $P=0.03)$ and in five of the six years when considered individually $(P<0.09$ in 2007, 2008 and 2009; $P<0.04$ in 2011 and 2012). Recall that the shallow irrigation treatment (ct-s) was applied such that the soil water content (SWC) was roughly the same as that of the elevated $\mathrm{CO}_{2}$ treatment $(\mathrm{Ct})$; the deep irrigation (ct-d) applied was the same amount as the surface irrigation from the previous year. There was no difference $(P>0.2)$ in annual $R_{\text {eco }}$ between the elevated $\mathrm{CO}_{2}$ treatment and either irrigation treatment (Ct vs. ct-d or Ct vs. ct-s) for any of the years or when aggregated over the six-year period (Fig. 3). When compared to the control treatment, irrigation did enhance annual $R_{\text {eco }}$ for three years (Fig. 3; $P=0.03$ in 2007 for ct vs. ct-s, $P=0.06$ in 2011 for ct vs. ct-d, $P=0.001$ and 0.006 in 2012 for ct vs. ct-d and ct vs. ct-s, respectively).
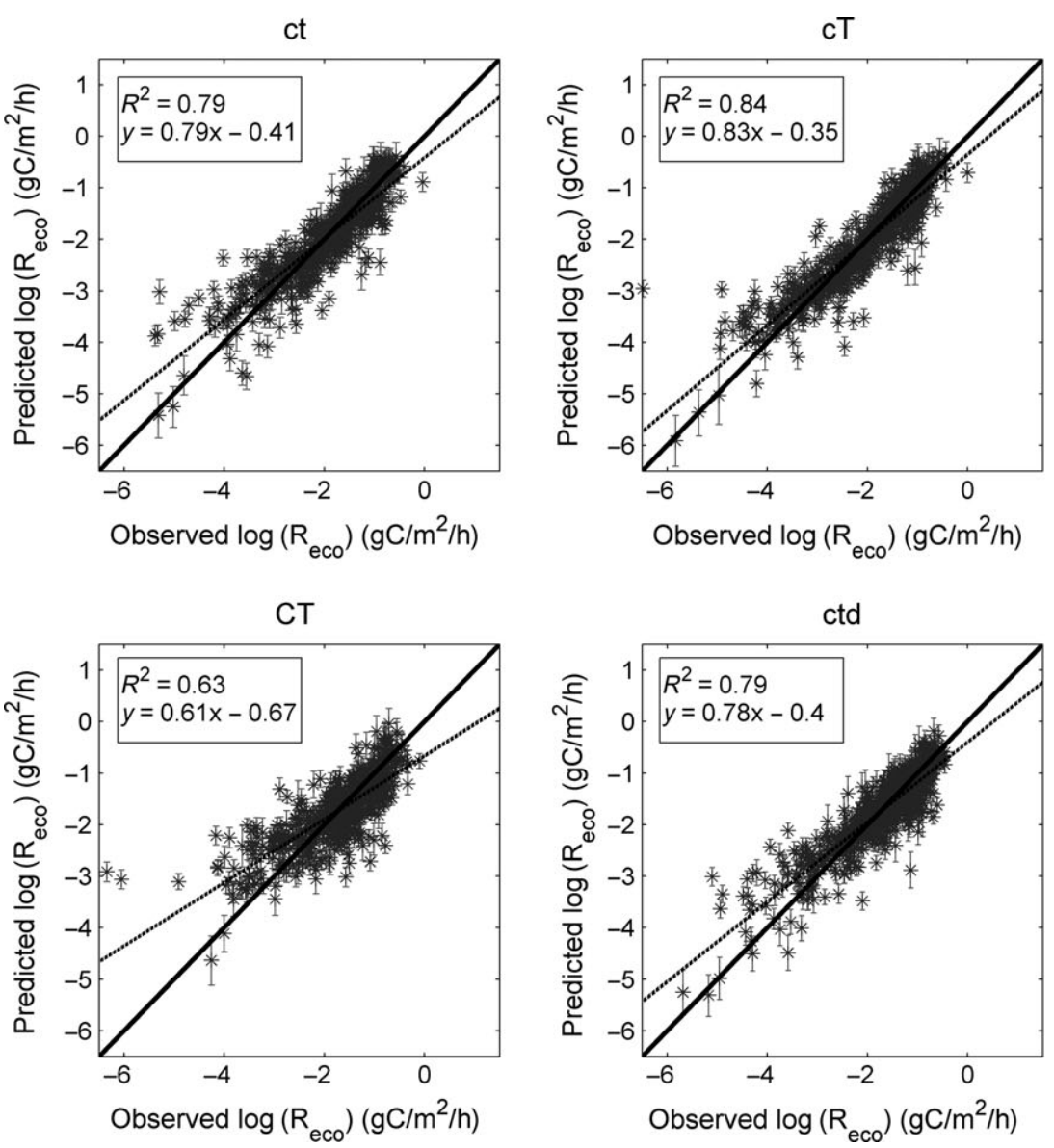
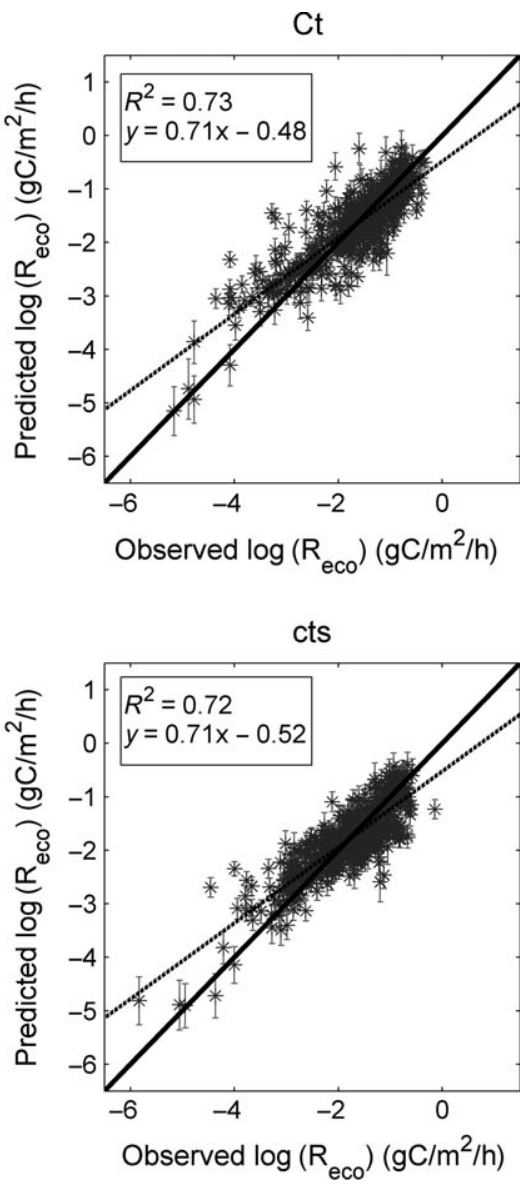

Fig. 1 Observed vs. predicted $\log \left(\mathrm{R}_{\mathrm{eco}}\right)$ for each treatment. The predicted values are the posterior means and central $95 \% \mathrm{credible}$ intervals for replicated observations (Gelman et al., 2013) of $\log \left(\mathrm{R}_{\mathrm{eco}}\right)$, based on Eqns (1) and (2). Treatments codes involve combinations of: c (ambient $\mathrm{CO}_{2}$ ), $\mathrm{C}$ (elevated $\mathrm{CO}_{2}$ ), t (no warming), $\mathrm{T}$ (warming), d (deep irrigation), or s (shallow irrigation). 

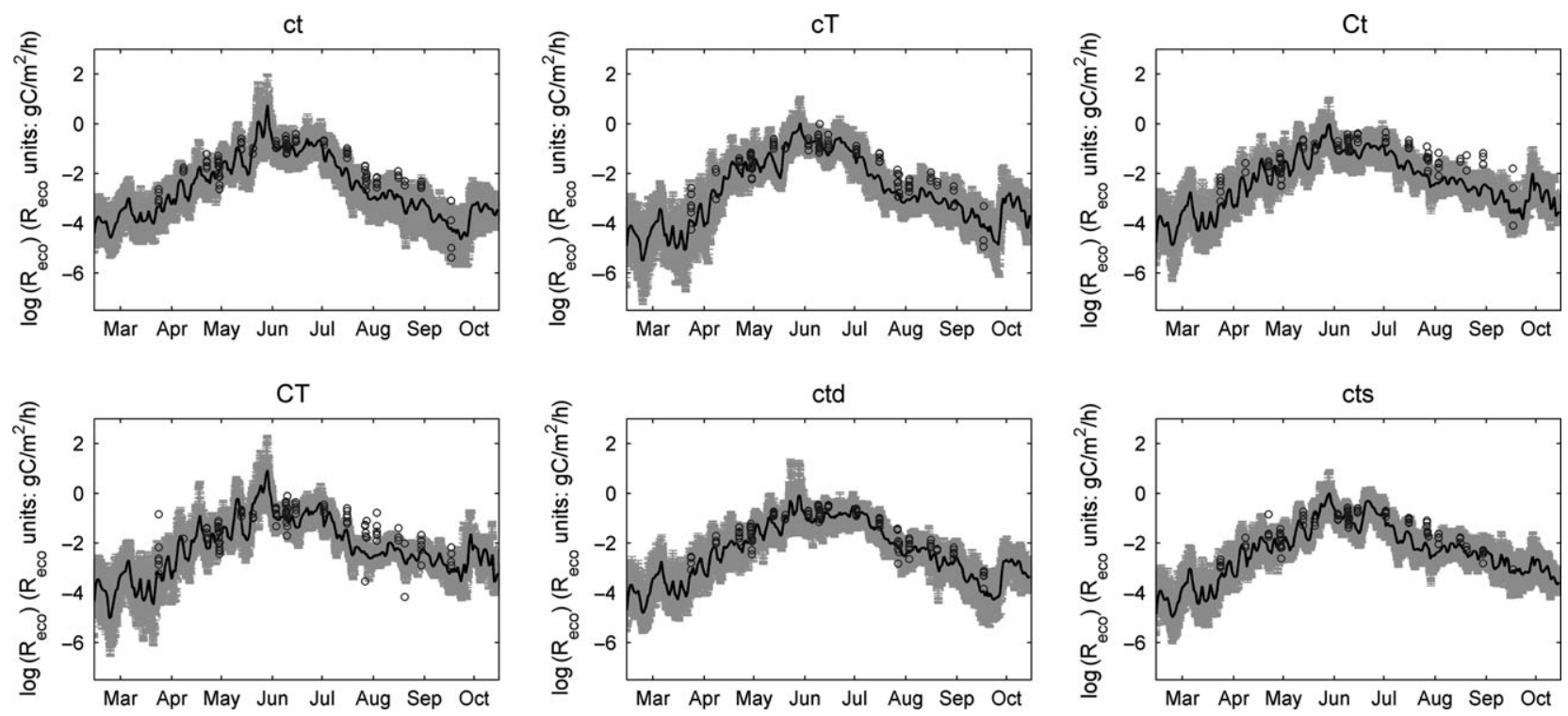

Fig. 2 Time series of predicted $\log \left(R_{\text {eco }}\right)$ for each treatment in 2009, represented by the posterior means for the daily values (black line) and central $95 \%$ credible intervals on the hourly time-scale (grey region). The circles denote observations of log $\left(R_{\text {eco }}\right)$. See Fig. 1 legend for treatment codes. Time series for the other years are presented in Fig. S1a-e.

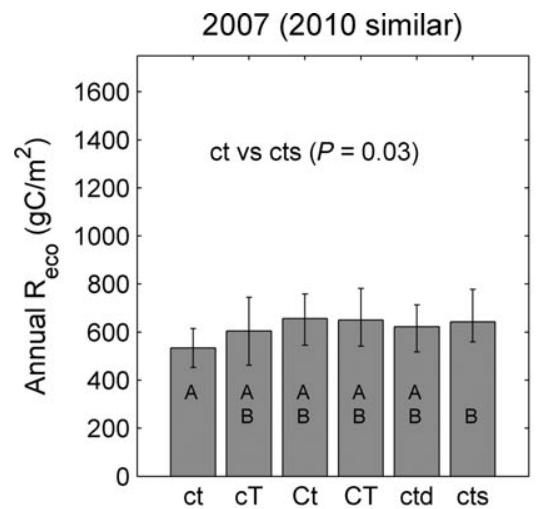

2011

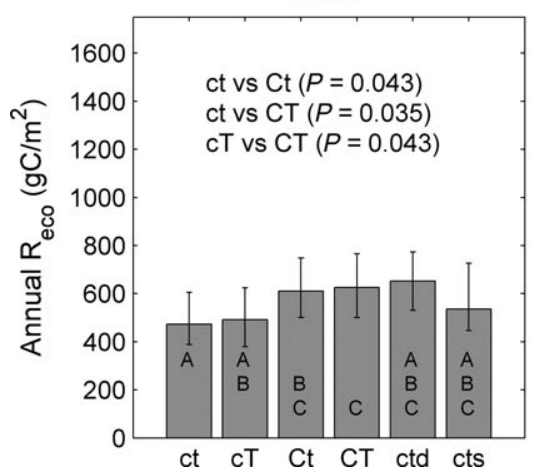

2008

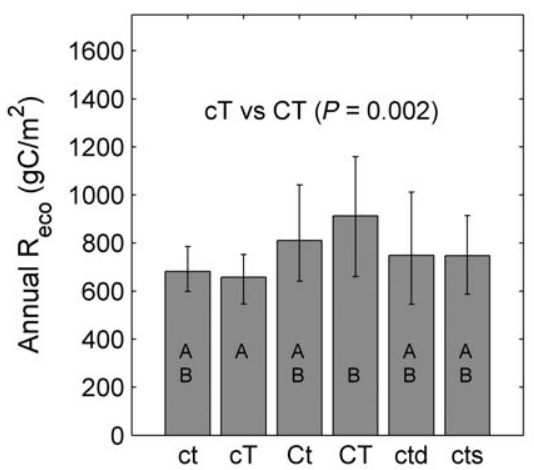

2012

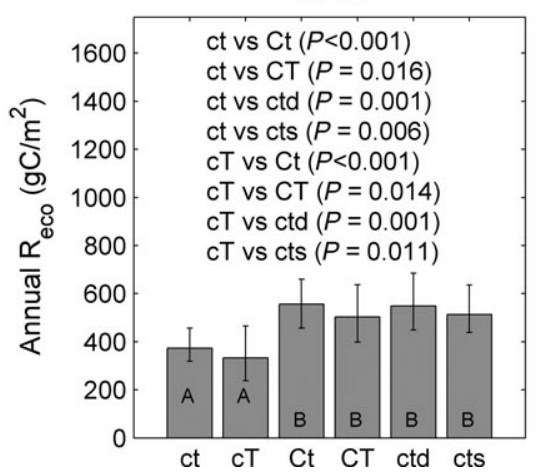

2009

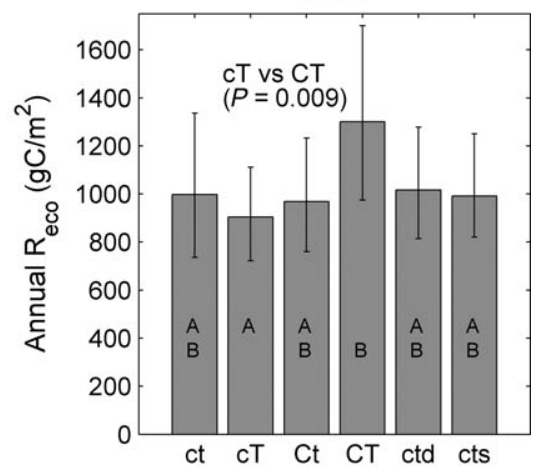

2007-2012

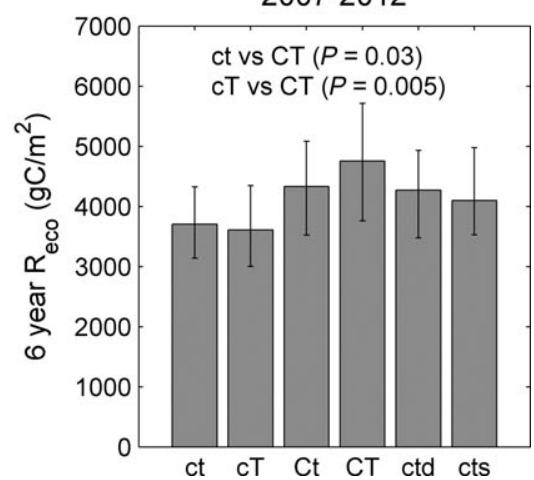

Fig. 3 Annual $R_{\text {eco }}$ for each treatment and each study year and across all six years is shown. Bars denote the posterior means and the error bars represent the central 95\% credible intervals. The letters inside the bars indicate statistically significant (at the 5\% level) differences among treatments, and the Bayesian $P$ values for significantly different treatment pairs are provided in each panel. The results for 2010 are not shown since they look very similar to the 2007 results. See Fig. 1 legend for treatment codes. 

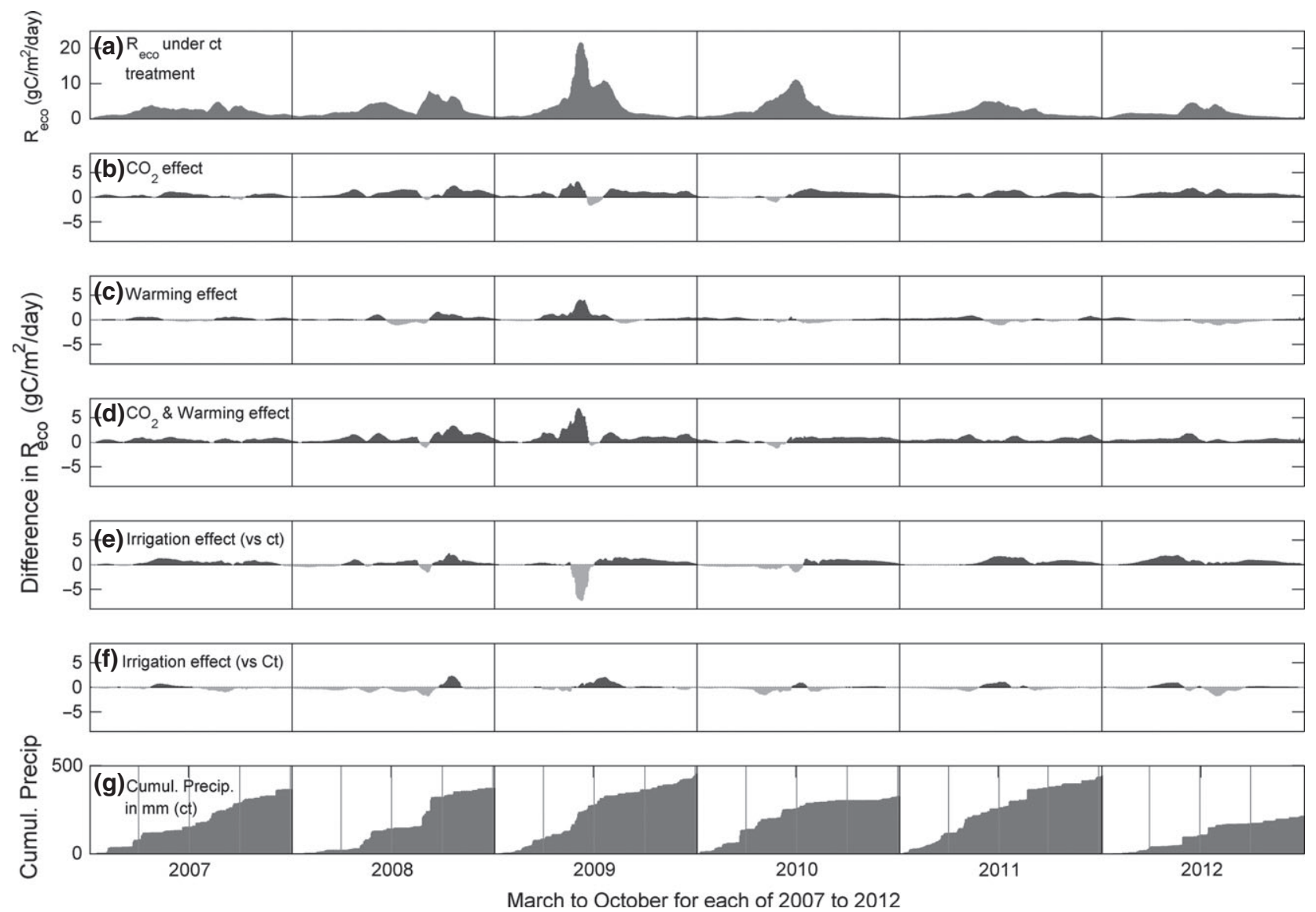

Fig. 4 Time-series of posterior means of daily contrasts to evaluate treatment-level differences in daily predicted $R_{\text {eco }}$ (a) Posterior means for daily $\mathrm{R}_{\text {eco }}$ under the ambient treatment (ct) are shown for reference. Five different treatment contrasts were computed: (b) effect of $\mathrm{CO}_{2}$ : $(\mathrm{Ct}+\mathrm{CT}) / 2-(\mathrm{ct}+\mathrm{cT}) / 2$; (c) effect of warming: $(\mathrm{cT}+\mathrm{CT}) / 2-(\mathrm{ct}+\mathrm{Ct}) / 2$; (d) combined $\mathrm{CO}_{2}$ and warming effect: $\mathrm{CT}-\mathrm{ct}$; (e) effecting of watering relative to ambient conditions: (cts+ctd) $/ 2-\mathrm{ct}$; (f) effect of watering relative to elevated $\mathrm{CO}_{2}$ : (cts+ctd) $/ 2-\mathrm{Ct}$. For ease of presentation, the credible intervals are not shown. For panels (b)-(f), the dark grey region indicates a positive treatment effect, while the light grey region denotes a negative effect. Panel $(\mathrm{g})$ shows the site level cumulative precipitation for each year.

We also evaluated treatment effects on $R_{\text {eco }}$ over shorter timescales by assessing temporal changes in pairwise differences of daily $R_{\text {eco }}$ for key pairs of treatments (Fig. 4). This analysis indicated that the daily predicted $R_{\text {eco }}$ was consistently enhanced under elevated $\mathrm{CO}_{2}$ (Fig. 4b). Warming increased and decreased $R_{\text {eco }}$ by approximately equal amounts within each season, but there were no consistent seasonal trends. Furthermore, the magnitude of the warming response was substantially less than under elevated $\mathrm{CO}_{2}$, except for the wettest year of 2009 where warming resulted in greater increases in $\mathrm{R}_{\text {eco }}$ (Fig. 4c). For 2009 only, the combined effect of warming and elevated $\mathrm{CO}_{2}$ enhanced $\mathrm{R}_{\text {eco }}$ to a greater extent than singularly under elevated $\mathrm{CO}_{2}$, but the effects of the two elevated $\mathrm{CO}_{2}$ treatments ( $\mathrm{Ct}$ and $\mathrm{CT}$ ) were comparable for the remaining years (Fig. $4 \mathrm{~b}$ vs. Fig. $4 \mathrm{~d}$ ). The $\mathrm{R}_{\text {eco }}$ daily differences between $\mathrm{Ct}$ and each of the two irrigation treatments (ct-s and ct-d) were not consistently positive or negative throughout the study period (Fig. 4f). In addition, for the irrigation treatments vs. ambient conditions (ct), the timing and magnitude of the irrigation effect (Fig. 4e) was similar to that of the $\mathrm{CO}_{2}$ effect (Fig. 4b).

Importance of current and antecedent soil conditions for understanding treatment effects on $R_{\text {eco }}$

Increases in current soil water content (SWC) are expected to increase the respiration base rate $\left(R_{\text {base }}\right)$, and this positive effect was similar for all treatments (Fig. 5d; Table 1, $P<0.001$ ). By contrast, current SWC did not affect the apparent temperature sensitivity of $\mathrm{R}_{\text {eco }}$ (i.e., $E_{o}$ ), which was also consistent across treatments (Fig. 5a; Table 1). Antecedent soil water content and antecedent soil temperature, either singly $\left(\mathrm{SWC}_{\mathrm{ant}}\right.$ or Soil $\mathrm{T}_{\text {ant }}$ ) or in combination with current conditions $\left(\mathrm{SWC} \times \mathrm{SWC}_{\mathrm{ant}}\right)$, were also important predictors of $\mathrm{R}_{\text {eсо }}$ 
Table 1 Summary of posterior estimates and Bayesian $P$-values for the effects parameters in the models for $E_{o}(\alpha$ parameters) and $\log \left(\mathrm{R}_{\text {base }}\right)$ ( $\beta$ parameters) [see Eqn (3)]. Black cells indicate $P \leq 0.001$, dark gray indicates $0.001<P \leq 0.01$, light gray indicates $0.01<P \leq 0.05$, and white indicates $P>0.05$. The signs ( + or - ) indicate whether an effect is positive or negative. For a particular effect parameter, the letters in the cells indicate significant treatment differences such that if two treatments do not share the same letter, $P<0.01$ for the associated treatment difference. See Fig. 1 legend for treatment codes

\begin{tabular}{|c|c|c|c|c|c|c|}
\hline Effect parameter & ct & cT & $\mathrm{Ct}$ & $\mathrm{CT}$ & ct-d & ct-s \\
\hline$\alpha_{1}(\mathrm{SWC})$ & A & A & A & A & A & A \\
\hline$\alpha_{2}\left(\mathrm{SWC}_{\mathrm{ant}}\right)$ & A & A & A & A & A & A \\
\hline$\alpha_{3}\left(S W C \times S W C_{\text {ant }}\right)$ & A & $\mathrm{A}$ & $\mathrm{A}$ & $\mathrm{A}$ & $\mathrm{A}$ & A \\
\hline$\alpha_{4}\left(\right.$ SoilT $\left._{\mathrm{ant}}\right)$ & $\overline{\mathrm{A}}$ & $\overline{\mathrm{AB}}$ & $\overline{\mathrm{B}}$ & $\bar{c}$ & $\overline{\mathrm{BC}}$ & $\overline{\mathrm{AB}}$ \\
\hline$\alpha_{5}\left(\mathrm{PAR}_{\mathrm{ant}} \times \mathrm{Gness}\right)$ & A & $\mathrm{A}$ & A & A & $\bar{A}$ & A \\
\hline$\alpha_{6}\left(\mathrm{VPD}_{\mathrm{ant}} \times \mathrm{Gness}\right)$ & A & A & $\begin{array}{l}+ \\
\mathrm{B}\end{array}$ & $\mathrm{AB}$ & $\mathrm{AB}$ & $\mathrm{AB}$ \\
\hline$\alpha_{7}\left(\mathrm{PAR}_{\mathrm{ant}} \times \mathrm{VPD}_{\mathrm{ant}} \times\right.$ Gness $)$ & A & $\mathrm{A}$ & $\mathrm{A}$ & $\overline{\mathrm{A}}$ & $\mathrm{A}$ & $\mathrm{A}$ \\
\hline$\alpha_{8}$ (Gness) & $\stackrel{+}{\mathrm{AB}}$ & $\begin{array}{c}+ \\
\mathrm{AB}\end{array}$ & $\stackrel{+}{\mathrm{AB}}$ & $\begin{array}{l}+ \\
\mathrm{A}\end{array}$ & B & $\mathrm{AB}$ \\
\hline$\beta_{1}(\mathrm{SWC})$ & $\begin{array}{l}+ \\
\mathrm{A}\end{array}$ & $\begin{array}{l}+ \\
\mathrm{A}\end{array}$ & $\begin{array}{l}+ \\
\mathrm{A}\end{array}$ & $\begin{array}{l}+ \\
\mathrm{A}\end{array}$ & $\begin{array}{l}+ \\
\mathrm{A}\end{array}$ & $\begin{array}{l}+ \\
\mathrm{A}\end{array}$ \\
\hline$\beta_{2}\left(\mathrm{SWC}_{\mathrm{ant}}\right)$ & $\stackrel{+}{\mathrm{AEF}}$ & $\stackrel{+}{\mathrm{AGH}}$ & $\stackrel{+}{+}$ & $\mathrm{CI}$ & $\stackrel{+}{\mathrm{DFG}}$ & $\mathrm{CH}$ \\
\hline$\beta_{3}\left(\mathrm{SWC} \times \mathrm{SWC}_{\mathrm{ant}}\right)$ & $\overline{\mathrm{AB}}$ & - & $\overline{\mathrm{AB}}$ & $\overline{\mathrm{A}}$ & - & $\stackrel{+}{\mathrm{E}}$ \\
\hline$\beta_{4}\left(\mathrm{PAR}_{\mathrm{ant}} \times\right.$ Gness $)$ & $\stackrel{+}{\mathrm{AB}}$ & $\mathrm{A}$ & $\stackrel{+}{\mathrm{AB}}$ & $\stackrel{+}{\mathrm{AB}}$ & $\stackrel{+}{\mathrm{B}}$ & $\mathrm{AB}$ \\
\hline$\beta_{5}\left(\mathrm{VPD}_{\mathrm{ant}} \times \mathrm{Gness}\right)$ & $\overline{\mathrm{A}}$ & $\mathrm{AB}$ & $\overline{\mathrm{B}}$ & $\overline{\mathrm{AB}}$ & $\overline{\mathrm{AB}}$ & $\overline{\mathrm{AB}}$ \\
\hline$\beta_{6}\left(\mathrm{PAR}_{\mathrm{ant}} \times \mathrm{VPD}_{\mathrm{ant}} \times\right.$ Gness $)$ & $\stackrel{+}{\mathrm{A}}$ & A & $\stackrel{+}{A}$ & $\stackrel{+}{\mathrm{A}}$ & + & A \\
\hline$\beta_{7}$ (Gness) & $\mathrm{A}$ & $\mathrm{A}$ & $\mathrm{A}$ & $\mathrm{A}$ & $\begin{array}{l}+ \\
\mathrm{A}\end{array}$ & $\begin{array}{l}+ \\
\mathrm{A}\end{array}$ \\
\hline
\end{tabular}

(Table 1, gray and black squares). The importance of the $\mathrm{SWC} \times \mathrm{SWC}_{\mathrm{ant}}$ term means that wet periods in the past (high $\mathrm{SWC}_{\mathrm{ant}}$ ) were associated with higher base respiration rates $\left(\beta_{2}>0\right.$; Table 1$)$; however, if a rain event occurred during a wet period, the response of $\mathrm{R}_{\text {eco }}$ to this increase in current SWC was dampened compared to the increase in $R_{\text {eco }}$ following an event occurring during a dry period $\left(\beta_{3}<0\right.$; Table 1$)$.

Antecedent belowground effects on $R_{\text {eco }}$ differed among treatments. Apparent temperature sensitivity $\left(E_{o}\right)$ was reduced during warm periods $\left(\alpha_{4}<0\right.$, Table 1$)$, but the size of the reduction was larger for the elevated $\mathrm{CO}_{2}$ treatments compared to the ambient treatments (Fig. 5b; ct vs. Ct or cT vs. CT, Bayesian $P=0.013$ and $P<0.001$, respectively). The respiration base rate $\left(\mathrm{R}_{\text {base }}\right)$ was enhanced as antecedent soil water increased $\left(\beta_{2}\right)$, but the enhancement was less pronounced under elevated $\mathrm{CO}_{2}$ (ct vs. $\mathrm{Ct}$ or cT vs. CT, $P=0.01$ and $P<0.001$, respectively). Under the combined effect of elevated $\mathrm{CO}_{2}$ and warming relative to the control treatment, the changes in $\mathrm{R}_{\mathrm{eco}}$ were most pronounced for every unit increase in either three of the belowground antecedent terms - antecedent soil water content $\left(\mathrm{SWC}_{\mathrm{ant}}\right)$, the interaction between current and antecedent soil water content $(S W C \times S W C a n t)$, and the antecedent soil temperature (Soil $\left.\mathrm{T}_{\text {ant }}\right)$ - compared to increases in any of the other model terms $(P<0.001$ for SoilT $_{\text {ant }}$ Fig. 5b; $P=0.001$ for SWC $_{\text {ant }} ; P=0.02$ for $\left.\mathrm{SWC} \times \mathrm{SWC}_{\mathrm{ant}}, \mathrm{Fig} .5 \mathrm{e}\right)$. These findings suggest that differences in annual $\mathrm{R}_{\text {eco }}$ among under elevated $\mathrm{CO}_{2}$ and the combined effect of elevated $\mathrm{CO}_{2}$ and warming (Fig. 3) are most likely driven by differential effects of antecedent soil water $\left(\mathrm{SWC}_{\mathrm{ant}}\right.$ and $\left.\mathrm{SWC} \times \mathrm{SWC}_{\mathrm{ant}}\right)$ and antecedent soil temperature (SoilT $\mathrm{ant}_{\mathrm{at}}$ ).

\section{Importance of aboveground factors for understanding treatment effects on $R_{\text {eco }}$}

The aboveground covariates - namely antecedent photosynthetically active radation $\left(\mathrm{PAR}_{\mathrm{ant}}\right)$, antecedent 
(a) $\alpha_{1}$ (SWC term in Eo)

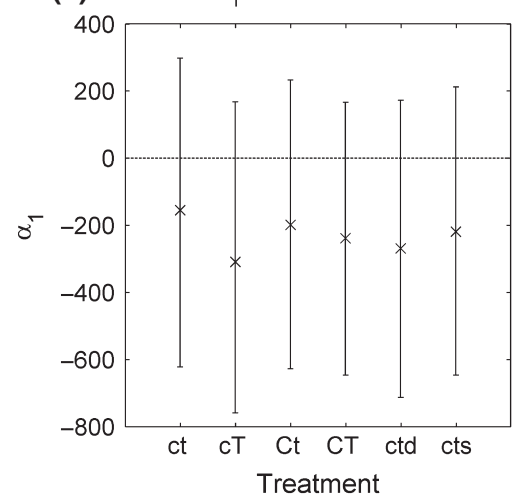

(d)

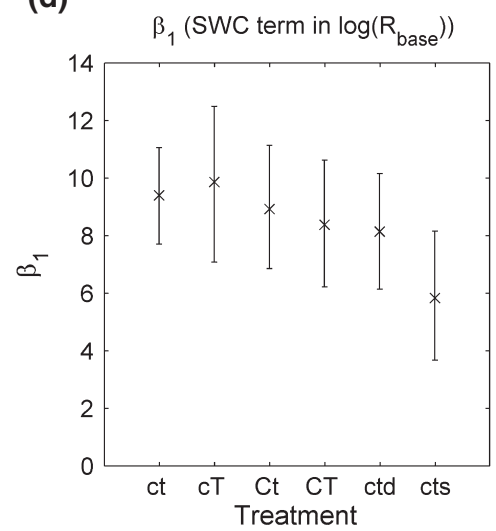

(b) $\quad \alpha_{4}$ (SoilTemp ant term in Eo)

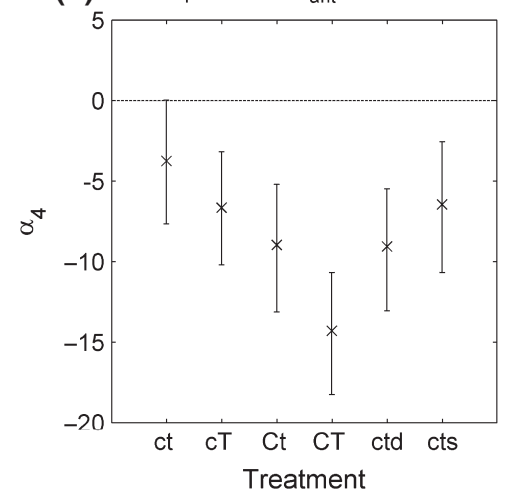

(e)

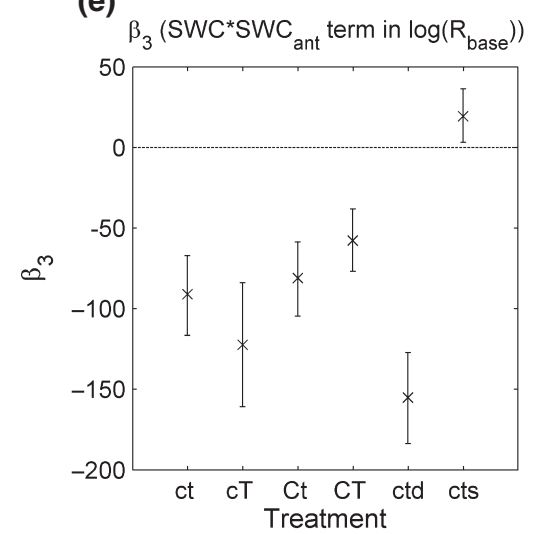

(c) $\alpha_{7}\left(\mathrm{PAR}_{\mathrm{ant}} \mathrm{VPD}_{\text {ant }}{ }^{*}\right.$ Gness term in Eo)

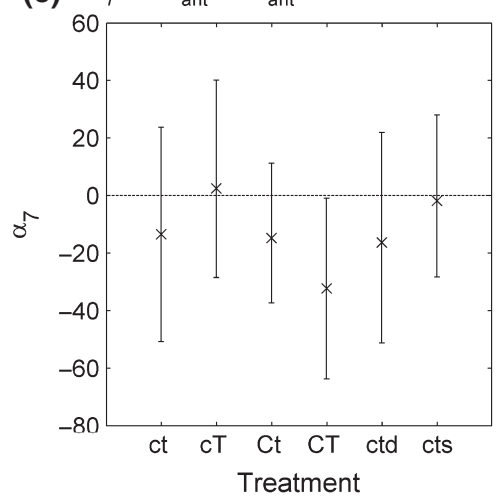

(f)

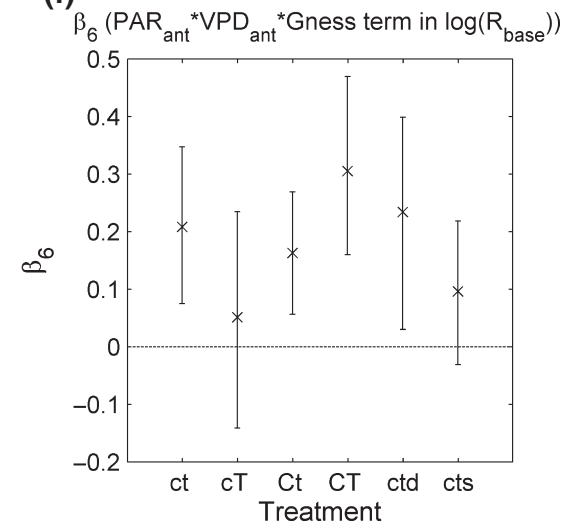

Fig. 5 Posterior means and central 95\% credible intervals (CIs) of a subset of effects parameters in the $E_{o}$ model (panels a-c) and the $\log \left(\mathrm{RE}_{\text {base }}\right)$ model (panels $\left.\mathrm{d}-\mathrm{f}\right)$. Covariates shown include current soil water content $(\mathrm{SWC})$, antecedent soil temperature (Soil $\left.\mathrm{T}_{\mathrm{ant}}\right)$, antecedent vapor pressure deficit $\left(\mathrm{VPD}_{\mathrm{ant}}\right)$, vegetation greenness (Gness), and antecedent soil water content $\left(\mathrm{SWC}_{\mathrm{ant}}\right)$. The dashed horizontal line represents zero, and 95\% CIs that overlap with zero indicate a non-significant effect. See Fig. 1 legend for treatment codes.

vapor pressure deficit $\left(\mathrm{VPD}_{\mathrm{ant}}\right)$, and vegetation greenness (Gness) - and their interactions [Eqn (4)] are important for predicting $R_{\text {eco }}$ (Table 1 , gray and black squares). However, their importance is less than those of the belowground covariates - namely current and antecedent soil water content and antecedent soil temperature $\left(\mathrm{SWC}, \mathrm{SWC}_{\mathrm{ant}}\right.$, and $\mathrm{SWC} * \mathrm{SWC}_{\mathrm{ant}}$, SoilT $\mathrm{ant}$; Table 1). Aboveground covariates generally had greater influence on the $\mathrm{R}_{\text {base }}$ rather than the $E_{o}$ component of $R_{\text {eco }}$ (Fig. 5c,f; Table 1). Of the aboveground covariates, vegetation greenness was the most important one influencing the apparent temperature sensitivity of $\mathrm{R}_{\text {eco }}\left(E_{0}\right)$ such that increases in it increased the apparent temperature sensitivity of $R_{\text {eco. However, }}$. the strength of the vegetation greenness effect on $R_{\text {eco }}$ varied among treatments (Table 1). Conversely, vegetation greenness and its interactions with antecedent PAR and antecedent VPD were the most important predictors of the respiration base rate $\left(R_{\text {base }}\right)$, suggesting that $R_{\text {base }}$ is more strongly coupled to photosynthesis than to the amount of active vegetation present (vegetation greenness; Table 1). Although the direction (positive or negative) of each aboveground effect was consistent across treatments, the magnitude and relative importance of the effects of the aboveground factors on $R_{\text {base }}$ varied among treatments. For example, the interactive effect of antecedent photosynthetically active radiation, antecedent vapor pressure deficit, and vegetation greenness $\left(\mathrm{PAR}_{\mathrm{ant}} \times \mathrm{VPD}_{\mathrm{ant}} \times \mathrm{G}-\right.$ ness) is positive for all six treatments (i.e., $\beta_{6}>0$, Table 1), but $\beta_{6}$ is more positive under the interaction of elevated $\mathrm{CO}_{2}$ and warming (Fig. 5f).

\section{Quantifying the timescales of the antecedent effects}

The effect of antecedent vapor pressure deficit (VPD) on $\mathrm{R}_{\text {eco }}$ varied across time. Specifically, VPD conditions experienced the first three (of seven) days prior to the $R_{\text {eco }}$ measurement were the most important for predicting $R_{\text {eco; }}$ that is, these days were associated with the highest weights $\left[W_{X}\right.$, Eqn (5)] for all treatments, with days 1 (yesterday) and 3 into the past having the greatest importance under the $\mathrm{ct}, \mathrm{CT}, \mathrm{Ct}$, and $\mathrm{CT}$ treatments (Fig. S2). For the other three antecedent 
covariates - namely antecedent soil water content, antecedent soil temperature, and antecedent photosynthetically active radiation $\left(\mathrm{SWC}_{\mathrm{ant}}, \mathrm{SoilT}_{\mathrm{ant}}\right.$, and $\left.\mathrm{PAR}_{\mathrm{ant}}\right)$ - the weights tended to be indistinguishable across all treatments and past time periods (Fig. S2).

\section{Consequences of not including antecedent effects}

Excluding antecedent conditions from the $\mathrm{R}_{\text {eco }}$ model generally resulted in increases in the predicted, annual 6-year $\mathrm{R}_{\mathrm{eco}}$, increasing $3.9 \%$ under deep irrigation (ctd), $7.7 \%$ under the control treatment (ct), $\sim 10 \%$ under warming (cT) and elevated $\mathrm{CO}_{2}(\mathrm{Ct})$, and $17.8 \%$ under surface irrigation (ct-s). The only exception was the combined $\mathrm{CO}_{2}$ and warmed treatment (CT) treatment, where exclusion of antecedent effects resulted in a $3.6 \%$ reduction in the predicted 6-year $R_{\text {eco }}$.

\section{Discussion}

Consequences of warming, elevated $\mathrm{CO}_{2}$, and altered soil moisture for $R_{\text {eco }}$ over annual to multiyear timescales

Our Bayesian synthesis approach allowed us to simultaneously evaluate the importance of multiple environmental and biotic drivers at different timescales. Thus, our analysis provided insight into to annual and multiyear effects of global change treatments, seasonal, weekly, and daily effects of antecedent conditions and vegetation activity, and daily and subdaily effects of concurrent changes in above- and belowground environmental conditions on $\mathrm{R}_{\mathrm{eco}}$. The analysis also allowed us to partition the effects of these environmental and biotic factors on the apparent temperature sensitivity $\left(E_{o}\right)$ vs. the respiration base rate ( $\left.\mathrm{R}_{\text {base }}\right)$, thus providing insights into potential mechanisms affecting $R_{\text {eco }}$ over these different timescales. Additionally, our stochastic approach to incorporating antecedent covariates has been implemented in only a handful of very recent studies, and this approach is expected to provide more realistic inferences about the importance of past conditions.

Our model of hourly and annual $\mathrm{R}_{\mathrm{eco}}$ suggests that annual $\mathrm{R}_{\text {eco }}$ is stimulated under elevated $\mathrm{CO}_{2}$ in four of the six years of the PHACE experiment at the $5 \%$ level of statistical significance, resulting in an overall stimulation across the 2007-2012 study period. These findings are consistent with a recent PHACE study that used a linear interpolation technique to obtain annual $R_{\text {eco }}$ sums for 2007-2010 (Pendall et al., 2013), which reported elevated $\mathrm{CO}_{2}$ effects under both ambient and increased temperature conditions. In contrast, we mainly found that elevated $\mathrm{CO}_{2}$ stimulated $\mathrm{R}_{\mathrm{eco}}$ only under warming. When warming was combined with elevated $\mathrm{CO}_{2}, \mathrm{R}_{\mathrm{eco}}$ increased across most of the duration of the PHACE experiment, but against our initial expectations, warming by itself did not significantly affect annual $R_{\text {eco. }}$ This appears to be in contrast to the findings of Pendall et al. (2013), who showed a significant main effect of warming on annual $R_{\text {eco }}$ for two (2007 and 2010) of the four years in their study. However, our results also suggest a trend toward the enhancement of $R_{\text {eco }}$ under warming, but due to our more thorough error propagation, the associated higher uncertainty estimates resulted in fewer significant warming and elevated $\mathrm{CO}_{2}$ effects. In particular, our method builds on the analysis of Pendall et al. (2013) by employing a more process-based modeling approach that quantifies the environmental drivers of $R_{\mathrm{eco}}$ in addition to treatment effects. Such process-based models are recommended for gap-filling time series data (Desai et al., 2008). Thus, we used our model to estimate hourly $\mathrm{R}_{\text {eco }}$ on nonmeasurement days, enabling us to represent daily and subdaily variation in $R_{\text {eco. }}$. Furthermore, our Bayesian approach also allowed for the propagation of the uncertainty associated with these hourly estimates, thus providing potentially more realistic estimates of the range of possible annual $R_{\text {eco }}$ values.

An important contribution of our analysis involving six years of data is that the effects of warming differed between wet and dry years. In a dry year (e.g., 2012), warming likely exacerbated soil water deficits (Ciais et al., 2005; Morgan et al., 2011), which led to lower $R_{\text {eco }}$ in 2012 (Fig. 3). However, in a wet year, warming increased microbial activity and thus decomposition rates (Nie et al., 2013), which helps to explain our predicted amplification of annual $\mathrm{R}_{\text {eco }}$ under both warming and elevated $\mathrm{CO}_{2}$ in 2009 (Fig. 3). Aboveground biomass production was also higher in 2009 (Morgan et al., 2011), likely paralleled by increased root respiration and potentially greater priming effects (Carrillo et al., 2011), which together would enhance overall higher $\mathrm{R}_{\text {eco. }}$.

The importance of moisture for annual $R_{\text {eco }}$ can also be inferred by evaluating the effects of the irrigation treatments. The main goal of applying the shallow irrigation treatment was to determine whether the stimulation of $\mathrm{R}_{\text {eco }}$ under elevated $\mathrm{CO}_{2}$ was the direct result of elevated $\mathrm{CO}_{2}$ or an indirect effect of an increase in soil water content (SWC) associated with elevated $\mathrm{CO}_{2}$ due to, for example, higher plant water-use efficiency under elevated $\mathrm{CO}_{2}$ (Pendall et al., 2003). Annual $\mathrm{R}_{\text {eco }}$ did not differ between elevated $\mathrm{CO}_{2}$ and watered plots, suggesting that elevated $\mathrm{CO}_{2}$ indirectly stimulated $\mathrm{R}_{\text {eco }}$ via a positive effect on SWC. However, for all but two years, annual $\mathrm{R}_{\text {eco }}$ also did not differ between watered and ambient $\mathrm{CO}_{2}$ plots, suggesting that such water 
savings is likely only one of several factors that can influence $\mathrm{R}_{\text {eco }}$ under elevated $\mathrm{CO}_{2}$; other potential factors are increases in root biomass (Carrillo et al., 2014), labile C pools (Carrillo et al., 2011), or priming of soil organic matter decomposition (Nie et al., 2013).

\section{Importance of current and antecedent soil water and temperature for understanding variation in $R_{e c o}$ and its long-term response to warming and elevated $\mathrm{CO}_{2}$}

Overall, water availability was critical for most aspects

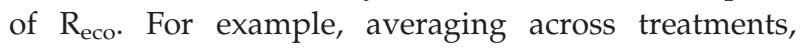
annual $R_{\text {eco }}$ was positively correlated with total annual precipitation (Fig. S3); variation in this relationship points to the importance of the seasonal distribution of precipitation (Huxman et al., 2004; Cable et al., 2008; Patrick et al., 2009) and legacy effects of past precipitation (Schwinning et al., 2004). For example, 2008 had the second-lowest annual precipitation, but the secondhighest annual $R_{\text {eco. }}$. Most of the precipitation in 2008 was delivered in two large storms (one in June, one in September) that occurred after 2-3 months of virtually no precipitation, and the timing of daily $R_{\text {eco }}$ peaked corresponded to the timing of these two events (Fig. 4g). This confirms other reports of exceptionally large enhancements of ecosystem and soil $\mathrm{CO}_{2}$ fluxes following rain events that break long dry spells in arid ecosystems ( $\mathrm{Xu}$ et al., 2004; Sponseller, 2007; Cable et al., 2008, 2011; Thomas et al., 2008) and also highlights the importance of past precipitation patterns for predicting $R_{\text {eco. }}$ Moreover, although 2010 was one of the driest study years, it had the third-highest annual $R_{\text {eco, suggesting a legacy effect of the preceding wet }}$ year on $R_{\text {eco }}$ as well as plant production (Nippert et al., 2006; Ogle et al., 2015).

The antecedent effects in our model represent legacy effects over shorter timescales (e.g., daily to weekly), and most antecedent covariates affected $R_{\text {eco }}$ similarly across the different global change treatments. For example, the directions (positive or negative) of the antecedent soil water effect on $R_{\text {eco }}$ were the same across all six treatments (Table 1). Increases in current or antecedent SWC ( $\left.\mathrm{SWC}_{\text {ant }}\right)$ have been shown to stimulate $\mathrm{R}_{\text {eco }}$ (Davidson et al., 1998), but we also found a negative interaction between current and antecedent SWC (Table 1), which is consistent with other studies of soil or ecosystem respiration in semiarid grasslands (Huxman et al., 2004; Xu et al., 2004; Harper et al., 2005; Chou et al., 2008) and deserts (Xu et al., 2004; Sponseller, 2007; Cable et al., 2008, 2011; Thomas et al., 2008; Barron-Gafford et al., 2014; Oikawa et al., 2014). This negative interaction indicates that increased SWC stimulates a greater $R_{\text {eco }}$ response if the rain event occurs during a dry vs. wet period. Under extremely wet con- ditions (very high $S W C_{a n t}$ ), it is possible that a rain event could reduce $R_{\mathrm{eco}}$, potentially reflecting oxygen limitations of respiration (Skopp et al., 1990; Davidson et al., 2012) or constraining the diffusivity of $\mathrm{CO}_{2}$ (Moldrup et al., 2004). Interestingly, our analysis suggests that SWC and $S_{W C}$ ant only affect $R_{\text {eco }}$ through their effects on the base rate $\left(R_{\text {base }}\right)$, whereas other studies (Cable et al., 2011, 2013; Barron-Gafford et al., 2014) suggest that soil water conditions also affect the apparent temperature sensitivity of $R_{\text {eco. }}$.

Consistent across all six treatments, antecedent soil temperature (Soil $\mathrm{T}_{\text {ant }}$ ) most strongly affected the apparent temperature sensitivity $\left(E_{o}\right)$ of $R_{\text {eco, }}$ a trend suggestive of a Type I temperature acclimation response (Atkin \& Tjoelker, 2003) that can be amplified by longterm warming (Luo et al., 2001; Davidson et al., 2006; Tucker et al., 2013). For example, under elevated $\mathrm{CO}_{2}$ and warming (CT), this temperature acclimation response was significantly stronger (Soil $_{\text {ant }}$ parameter was more negative) than under the control treatment (ct) (Fig. 5b). In opposition to this finding, the 6-year $R_{\text {eco }}$ sum was significantly greater under CT (Fig. 3), which can be explained by $R_{\text {base }}$ being significantly greater under CT compared to ct, indicating that acclimation of $E_{o}$ was more than compensated by enhanced $R_{\text {base }}$ in the CT treatment. This enhancement of $R_{\text {eco }}$ under the combined effect of elevated $\mathrm{CO}_{2}$ and warming agrees with findings from a laboratory incubation experiment using soil microbes from the same site (Nie et al., 2013). We speculate that the soil organic matter priming mechanism (Pendall et al., 2003; Dijkstra et al., 2013), which would most likely affect $R_{\text {base }}$ more than $E_{o}$, may be more important than the direct effects of temperature change for understanding positive climate- $\mathrm{CO}_{2}$ feedbacks (Cox et al., 2000; Luo, 2007; Luo et al., 2008).

\section{Importance of aboveground factors for understanding variation in $R_{\text {eco }}$ and its long-term response to warming and elevated $\mathrm{CO}_{2}$}

Our results suggest that vegetation greenness was an important predictor of $R_{\text {eco }}$ by affecting the base rate $\left(R_{\text {base }}\right)$, especially when interacting with antecedent vapor pressure deficit $\left(\mathrm{VPD}_{\mathrm{ant}} \times \mathrm{Gness}\right)$ and, to a lesser extent, when interacting with antecedent photosynthetically active radiation ( $\left.\mathrm{PAR}_{\mathrm{ant}} \times \mathrm{Gness}\right)$. These interactions were consistently negative with VPD and positive with PAR across all treatments, indicating that high VPD and/or low PAR leads to a reduction in predicted $R_{\text {eco }}$ relative to the amount of active vegetation present. This likely reflects the effects of these two drivers on photosynthesis. The coupling of $R_{\text {eco }}$ and PAR can have important implications for soil respiration (Craine et al., 
1999). In addition, high VPD is expected to result in greater stomatal closure (Oren et al., 1999; Damour et al., 2010), reducing GPP and thus root respiration (Yiqi \& Zhou, 2010). In forests, maximum leaf area index - like vegetation greenness, a proxy for vegetation productivity - has been found to be a robust predictor to soil respiration across 17 different forest and shrubland sites in Europe and North America (Reichstein et al., 2003). Under elevated $\mathrm{CO}_{2}$, the interaction between VPD and vegetation greenness is more negative, suggesting an increased sensitivity of stomatal conductance to VPD, which may increase plant wateruse efficiency and reduce drawdown of soil water.

Apparent temperature sensitivity $\left(E_{o}\right)$ is an emergent ecosystem property that results from the covariation of many factors with soil temperature, such as soil moisture, substrate availability, and biological activity (Davidson \& Janssens, 2006; Sierra, 2012). In this study, $E_{o}$ was affected by the relative amount of slowly varying ( $\sim$ weekly) plant biomass or phenology, but not by fast timescale drivers (VPD and PAR). In particular, $E_{o}$ was expected to increase with increasing vegetation greenness (plant biomass) in nonirrigated plots (Table 1), which was particularly pronounced under the combination of elevated $\mathrm{CO}_{2}$ and warming. This potentially reflects the influence of increased substrates or different substrate types on $E_{o}$ (Davidson et al., 2006; Hartley \& Ineson, 2008), assuming that greenness is a proxy for cumulative substrates and root activity. In contrast to $E_{o}$, the main effect of greenness on $R_{\text {base }}$ was only significant under irrigation (Table 1), and the statistically significant interaction of greenness and VPD and/or PAR suggests that $R_{\text {base }}$ is more strongly coupled to dynamic photosynthesis than plant standing crop. In general, our analysis indicates that aboveground plant activity, whether it be via photosynthesis (for $\mathrm{R}_{\text {base}}$ ) or living biomass (for $E_{o}$ ), is critical for predicting $R_{\text {eco }}$.

\section{Conclusions}

We presented a novel analysis of six years of $R_{\text {eco }}$ data from a long-term multifactor global change experiment. In summary, our work suggests that $R_{\text {eco }}$ predictions can be improved by including the combined effects of antecedent soil moisture, antecedent soil temperature, and aboveground plant activity in future modeling efforts. In fact, the current version of CENTURY, which operates at the daily timescale, illustrates a step toward this goal in that it now includes the effects of moisture conditions prior to rain events and temperature-dependent temperature sensitivity when computing respiration (Del Grosso et al., 2005; Chamberlain et al., 2011). Our results indicate that excluding the effects of antecedent environmental conditions could result in biased $(-3.6-17.8 \%)$ forecasts of six-year $\mathrm{R}_{\text {eco }}$ under different global change scenarios. At the landscape to global scale, this suggests that the stimulation of grassland $\mathrm{R}_{\text {eco }}$ under elevated $\mathrm{CO}_{2}$ may not be as large as currently predicted (Gilmanov et al., 2010). We recommend that along with past environmental conditions, ecosystem models include aboveground-belowground linkages, both of which appear critical to predicting $\mathrm{R}_{\mathrm{eco}}$ under current and future climate and $\mathrm{CO}_{2}$ conditions.

\section{Acknowledgements}

This material is based upon work supported by the US Department of Agriculture Agricultural Research Service Climate Change, Soils \& Emissions Program, USDA-CSREES Soil Processes Program (\#2008-35107-18655), US Department of Energy Office of Science (BER), through the Terrestrial Ecosystem Science program (\#DE-SC0006973) and the Western Regional Center of the National Institute for Climatic Change Research, and the National Science Foundation (DEB\#1021559). Any opinions, findings, and conclusions or recommendations expressed in this material are those of the author(s) and do not necessarily reflect the views of the National Science Foundation. We thank David Smith for infrastructure maintenance, and Amanda Brennan, Yana Sorokin, Jana Heisler-White, and numerous undergraduate researchers for their help with collecting the data.

\section{References}

Adair CE, Reich PB, Trost JJ, Hobbie SE (2011) Elevated CO2 stimulates grassland soil respiration by increasing carbon inputs rather than by enhancing soil moisture. Global Change Biology, 17, 3546-3563.

Arora VK, Boer GJ, Friedlingstein P et al. (2013) Carbon-concentration and carbon-climate feedbacks in CMIP5 Earth system models. Journal of Climate, 26, 5289-5314.

Atkin OK, Tjoelker MG (2003) Thermal acclimation and the dynamic response of plant respiration to temperature. Trends in Plant Science, 8, 343-351.

Bachman S, Heisler-White JL, Pendall E, Williams DG, Morgan JA, Newcomb J (2010) Elevated carbon dioxide alters impacts of precipitation pulses on ecosystem photosynthesis and respiration in a semi-arid grassland. Oecologia, 162, 791-802.

Bardgett RD (2011) Plant-soil interactions in a changing world. F1000 Biology Reports, $3,1-6$.

Barron-Gafford GA, Cable JM, Bentley LP, Scott RL, Huxman TE, Jenerette GD, Ogle K (2014) Quantifying the timescales over which exogenous and endogenous conditions affect soil respiration. New Phytologist, 202, 442-454.

Beer C, Reichstein M, Tomelleri E et al. (2010) Terrestrial gross carbon dioxide uptake: global distribution and covariation with climate. Science, 329, 834-838.

Bernhardt E, Barber J, Pippen J, Taneva L, Andrews J, Schlesinger W (2006) Longterm effects of free air $\mathrm{CO} 2$ enrichment (FACE) on soil respiration. Biogeochemistry, 77, 91-116.

Bond-Lamberty B, Thomson A (2010) Temperature-associated increases in the global soil respiration record. Nature, 464, 579-582.

Booth DT, Cox SE, Berryman RD (2006) Point sampling digital imagery with 'SamplePoint'. Environmental Monitoring and Assessment, 123, 97-108.

Cable JM, Ogle K, Williams DG, Weltzin JF, Huxman TE (2008) Soil texture drives responses of soil respiration to precipitation pulses in the Sonoran Desert: implications for climate change. Ecosystems, 11, 961-979.

Cable JM, Ogle K, Lucas RW et al. (2011) The temperature responses of soil respiration in deserts: a seven desert synthesis. Biogeochemistry, 103, 71-90.

Cable JM, Barron-Gafford GA, Ogle K, Pavao-Zuckerman M, Scott RL, Williams DG, Huxman TE (2012) Shrub encroachment alters sensitivity of soil respiration to temperature and moisture. Journal of Geophysical Research: Biogeosciences, 2005-2012, 117. 
Cable JM, Ogle K, Barron-Gafford GA et al. (2013) Antecedent conditions influence soil respiration differences in shrub and grass patches. Ecosystems, 16, 12301247.

Canadell JG, Le Quéré C, Raupach MR et al. (2007) Contributions to accelerating atmospheric $\mathrm{CO} 2$ growth from economic activity, carbon intensity, and efficiency of natural sinks. Proceedings of the National Academy of Sciences, 104, 18866-18870.

Carbone MS, Winston GC, Trumbore SE (2008) Soil respiration in perennial grass and shrub ecosystems: linking environmental controls with plant and microbial sources on seasonal and diel timescales. Journal of Geophysical Research: Biogeosciences, 2005-2012, 113.

Carrillo Y, Pendall E, Dijkstra FA, Morgan JA, Newcomb JM (2011) Response of soil organic matter pools to elevated $\mathrm{CO} 2$ and warming in a semi-arid grassland. Plant and Soil, 347, 339-350.

Carrillo Y, Dijkstra FA, Lecain D, Morgan JA, Blumenthal D, Waldron S, Pendall E (2014) Disentangling root responses to climate change in a semiarid grassland Oecologia, 175, 699-711.

Chamberlain JF, Miller SA, Frederick JR (2011) Using DAYCENT to quantify on-farm GHG emissions and $\mathrm{N}$ dynamics of land use conversion to $\mathrm{N}$-managed switchgrass in the Southern US. Agriculture, Ecosystems and Environment, 141, 332-341

Chou WW, Silver WL, Jackson RD, Thompson AW, Allen-Diaz B (2008) The sensitivity of annual grassland carbon cycling to the quantity and timing of rainfall. Global Change Biology, 14, 1382-1394.

Ciais P, Reichstein M, Viovy N et al. (2005) Europe-wide reduction in primary productivity caused by the heat and drought in 2003. Nature, 437, 529-533.

Clark JS (2003) Uncertainty and variability in demography and population growth: a hierarchical approach. Ecology, 84, 1370-1381.

Cox PM, Betts RA, Jones CD, Spall SA, Totterdell IJ (2000) Acceleration of global warming due to carbon-cycle feedbacks in a coupled climate model. Nature, 408, 184-187.

Craine JM, Wedin DA, Chapin Iii FS (1999) Predominance of ecophysiological controls on soil CO2 flux in a Minnesota grassland. Plant and Soil, 207, 77-86.

Cressie N, Calder CA, Clark JS, Hoef JMV, Wikle CK (2009) Accounting for uncertainty in ecological analysis: the strengths and limitations of hierarchical statistical modeling. Ecological Applications, 19, 553-570.

Damour G, Simonneau T, Cochard H, Urban L (2010) An overview of models of stomatal conductance at the leaf level. Plant, Cell and Environment, 33, 1419-1438.

Davidson EA, Janssens IA (2006) Temperature sensitivity of soil carbon decomposition and feedbacks to climate change. Nature, 440, 165-173.

Davidson E, Belk E, Boone RD (1998) Soil water content and temperature as independent or confounded factors controlling soil respiration in a temperate mixed hardwood forest. Global Change Biology, 4, 217-227.

Davidson EA, Janssens IA, Luo Y (2006) On the variability of respiration in terrestrial ecosystems: moving beyond Q10. Global Change Biology, 12, 154-164.

Davidson EA, Samanta S, Caramori SS, Savage K (2012) The Dual Arrhenius and Michaelis-Menten kinetics model for decomposition of soil organic matter at hourly to seasonal time scales. Global Change Biology, 18, 371-384.

Del Grosso S, Mosier A, Parton W, Ojima D (2005) DAYCENT model analysis of past and contemporary soil $\mathrm{N}_{2} \mathrm{O}$ and net greenhouse gas flux for major crops in the USA. Soil and Tillage Research, 83, 9-24.

Desai AR, Richardson AD, Moffat AM et al. (2008) Cross-site evaluation of eddy covariance GPP and RE decomposition techniques. Agricultural and Forest Meteorology, 148, 821-838

Dezi S (2011) Modelling the effects of nitrogen deposition and carbon dioxide enrichment on forest carbon balance.

Dieleman WI, Vicca S, Dijkstra FA et al. (2012) Simple additive effects are rare: a quantitative review of plant biomass and soil process responses to combined manipulations of CO2 and temperature. Global Change Biology, 18, 2681-2693.

Dijkstra FA, Carrillo Y, Pendall E, Morgan JA (2013) Rhizosphere priming: a nutrient perspective. Frontiers in Microbiology, 4, 1-8.

Drake JE, Gallet-Budynek A, Hofmockel KS et al. (2011) Increases in the flux of carbon belowground stimulate nitrogen uptake and sustain the long-term enhancement of forest productivity under elevated CO2. Ecology Letters, 14, 349-357.

Friedlingstein P, Cox P, Betts R et al. (2006) Climate-carbon cycle feedback analysis: results from the C4MIP model intercomparison. Journal of Climate, 19, 3337-3353.

Gelfand AE, Ghosh SK (1998) Model choice: a minimum posterior predictive loss approach. Biometrika, 85, 1-11.

Gelman A, Carlin JB, Stern HS, Rubin DB (2003) Bayesian Data Analysis. CRC press, London.

Gelman A, Carlin JB, Stern HS, Dunson DB, Vehtari A, Rubin DB (2013) Bayesian Data Analysis. CRC press, London.
Gilmanov TG, Aires L, Barcza Z et al. (2010) Productivity, respiration, and lightresponse parameters of world grassland and agroecosystems derived from fluxtower measurements. Rangeland Ecology and Management, 63, 16-39.

Harmon ME, Bond-Lamberty B, Tang J, Vargas R (2011) Heterotrophic respiration in disturbed forests: a review with examples from North America. Journal of Geophysical Research: Biogeosciences, 2005-2012, 116.

Harper CW, Blair JM, Fay PA, Knapp AK, Carlisle JD (2005) Increased rainfall variability and reduced rainfall amount decreases soil $\mathrm{CO} 2$ flux in a grassland ecosystem. Global Change Biology, 11, 322-334.

Hartley IP, Ineson P (2008) Substrate quality and the temperature sensitivity of soil organic matter decomposition. Soil Biology and Biochemistry, 40, 1567-1574.

Högberg P, Read DJ (2006) Towards a more plant physiological perspective on soil ecology. Trends in Ecology and Evolution, 21, 548-554

Högberg P, Nordgren A, Buchmann N et al. (2001) Large-scale forest girdling shows that current photosynthesis drives soil respiration. Nature, 411, 789-792.

Hui D, Verburg P, Arnone J, Luo Y (2008) Dynamics and partitioning of whole ecosystem respiration in a controlled grassland ecosystem. In: Abstract of the Ecological Society of America, 3-8 August, 2008. Milwaukee, Wisconsin.

Huxman TE, Snyder KA, Tissue D et al. (2004) Precipitation pulses and carbon fluxes in semiarid and arid ecosystems. Oecologia, 141, 254-268.

Jasoni RL, Smith SD, Arnone JA (2005) Net ecosystem CO2 exchange in Mojave Desert shrublands during the eighth year of exposure to elevated CO2. Global Change Biology, 11, 749-756.

Kimball B (2005) Theory and performance of an infrared heater for ecosystem warming. Global Change Biology, 11, 2041-2056.

Lloyd J, Taylor J (1994) On the temperature dependence of soil respiration. Functional Ecology, 8, 315-323.

Lunn D, Spiegelhalter D, Thomas A, Best N (2009) The BUGS project: evolution, critique and future directions. Statistics in Medicine, 28, 3049-3067.

Luo Y (2007) Terrestrial carbon-cycle feedback to climate warming. Annual Review of Ecology Evolution, and Systematics, 38, 683-712.

Luo Y, Wan S, Hui D, Wallace LL (2001) Acclimatization of soil respiration to warming in a tall grass prairie. Nature, $413,622-625$.

Luo Y, Gerten D, Le Maire G et al. (2008) Modeled interactive effects of precipitation, temperature, and [CO2] on ecosystem carbon and water dynamics in different climatic zones. Global Change Biology, 14, 1986-1999.

Miglietta F, Hoosbeek M, Foot J et al. (2001) Spatial and temporal performance of the MiniFACE (Free Air CO2 Enrichment) system on bog ecosystems in northern and central Europe. Environmental Monitoring and Assessment, 66, 107-127.

Moldrup P, Olesen T, Yoshikawa S, Komatsu T, Rolston DE (2004) Three-porosity model for predicting the gas diffusion coefficient in undisturbed soil. Soil Science Society of America Journal, 68, 750-759.

Morgan JA, Lecain DR, Pendall E et al. (2011) C4 grasses prosper as carbon dioxide eliminates desiccation in warmed semi-arid grassland. Nature, 476 202-205.

Nie M, Pendall E, Bell C, Gasch CK, Raut S, Tamang S, Wallenstein MD (2013) Positive climate feedbacks of soil microbial communities in a semi-arid grassland. Ecology Letters, 16, 234-241.

Nippert JB, Knapp AK, Briggs JM (2006) Intra-annual rainfall variability and grassland productivity: can the past predict the future? Plant Ecology, 184, 6574 .

Norby RJ, Zak DR (2011) Ecological lessons from free-air CO2 enrichment (FACE) experiments. Annual Review of Ecology, Evolution, and Systematics, 42, 181.

Norby RJ, Hanson PJ, O'neill EG et al. (2002) Net primary productivity of a CO2enriched deciduous forest and the implications for carbon storage. Ecological Applications, 12, 1261-1266.

Ogle K, Barber JJ (2008) Bayesian data-model integration in plant physiological and ecosystem ecology. In: Progress in Botany, pp. 281-311. Springer, Berlin, Heidelberg.

Ogle K, Barber JJ, Barron-Gafford GA et al. (2015) Quantifying ecological memory in plant and ecosystem processes. Ecology Letters, 18, 221-235.

Oikawa P, Grantz D, Chatterjee A, Eberwein J, Allsman L, Jenerette G (2014) Unifying soil respiration pulses, inhibition, and temperature hysteresis through dynamics of labile soil carbon and O2. Journal of Geophysical Research: Biogeosciences, 119, 521 536

Oren R, Sperry J, Katul G, Pataki D, Ewers B, Phillips N, Schäfer K (1999) Survey and synthesis of intra-and interspecific variation in stomatal sensitivity to vapour pressure deficit. Plant, Cell and Environment, 22, 1515-1526.

Parslow J, Cressie N, Campbell EP, Jones E, Murray L (2013) Bayesian learning and predictability in a stochastic nonlinear dynamical model. Ecological Applications, 23, 679-698. 
Parton WJ, Morgan JA, Wang G, Del Grosso S (2007) Projected ecosystem impact of the prairie heating and $\mathrm{CO} 2$ enrichment experiment. New Phytologist, 174, 823-834.

Patrick LD, Ogle K, Bell CW, Zak J, Tissue D (2009) Physiological responses of two contrasting desert plant species to precipitation variability are differentially regulated by soil moisture and nitrogen dynamics. Global Change Biology, 15, 1214-1229.

Pendall E, Leavitt SW, Brooks T et al. (2001) Elevated CO2 stimulates soil respiration in a FACE wheat field. Basic and Applied Ecology, 2, 193-201.

Pendall E, Del GS, King JY, Lecain DR, Milchunas DG (2003) Elevated atmospheric $\mathrm{CO} 2$ effects and soil water feedbacks on soil respiration components in a Colorado grassland. Global Biogeochemical Cycles, 17, 1046.

Pendall E, Bridgham S, Hanson PJ et al. (2004) Below-ground process responses to elevated $\mathrm{CO} 2$ and temperature: a discussion of observations, measurement methods, and models. New Phytologist, 162, 311-322.

Pendall E, Heisler-White JL, Williams DG, Dijkstra FA, Carrillo Y, Morgan JA, Lecain DR (2013) Warming reduces carbon losses from grassland exposed to elevated atmospheric carbon dioxide. PLOS ONE, 8, e71921.

Piao S, Ciais P, Friedlingstein P et al. (2008) Net carbon dioxide losses of northern ecosystems in response to autumn warming. Nature, 451, 49-52.

Polley HW, Briske DD, Morgan JA, Wolter K, Bailey DW, Brown JR (2013) Climate Change and North American Rangelands: trends, Projections, and Implications. Rangeland Ecology and Management, 66, 493-511.

Reichstein M, Rey A, Freibauer A et al. (2003) Modeling temporal and large-scale spatial variability of soil respiration from soil water availability, temperature and vegetation productivity indices. Global Biogeochemical Cycles, 17, 1-15.

Roy J, Mooney HA, Saugier B (2001) Terrestrial Global Productivity. Academic Press, San Diego, CA.

Rustad L, Campbell J, Marion G et al. (2001) A meta-analysis of the response of soil respiration, net nitrogen mineralization, and aboveground plant growth to experimental ecosystem warming. Oecologia, 126, 543-562.

Schwinning S, Sala OE, Loik ME, Ehleringer JR (2004) Thresholds, memory, and seasonality: understanding pulse dynamics in arid/semi-arid ecosystems. Oecologia, 141, 191-193.
Sierra CA (2012) Temperature sensitivity of organic matter decomposition in the Arrhenius equation: some theoretical considerations. Biogeochemistry, 108, 101-115.

Skopp J, Jawson M, Doran J (1990) Steady-state aerobic microbial activity as a function of soil water content. Soil Science Society of America Journal, 54, 16191625.

Sponseller RA (2007) Precipitation pulses and soil CO2 flux in a Sonoran Desert ecosystem. Global Change Biology, 13, 426-436.

Thomas AD, Hoon SR, Linton PE (2008) Carbon dioxide fluxes from cyanobacteria crusted soils in the Kalahari. Applied Soil Ecology, 39, 254-263.

Tucker CL, Bell J, Pendall E, Ogle K (2013) Does declining carbon-use efficiency explain thermal acclimation of soil respiration with warming? Global Change Biol ogy, 19, 252-263.

Vargas R, Carbone MS, Reichstein M, Baldocchi DD (2011) Frontiers and challenges in soil respiration research: from measurements to model-data integration. Biogeochemistry, 102, 1-13.

Wan S, Norby RJ, Ledford J, Weltzin JF (2007) Responses of soil respiration to elevated $\mathrm{CO} 2$, air warming, and changing soil water availability in a model old-field grassland. Global Change Biology, 13, 2411-2424.

Williams M, Schwarz PA, Law BE, Irvine J, Kurpius MR (2005) An improved analysis of forest carbon dynamics using data assimilation. Global Change Biology, 11, 89-105.

Xiao C-W, Yuste JC, Janssens I et al. (2003) Above-and belowground biomass and net primary production in a 73-year-old Scots pine forest. Tree Physiology, 23, 505-516.

Xu L, Baldocchi DD, Tang J (2004) How soil moisture, rain pulses, and growth alter the response of ecosystem respiration to temperature. Global Biogeochemical Cycles, $18,1-10$.

Yiqi L, Zhou X (2010) Soil Respiration and the Environment. Academic press, Burlington, MA.

Zelikova TJ, Pendall E, Williams DG, Hoenigman R, Blumenthal D, Morgan J (accepted) Precipitation controls ecosystem phenology and plant responses to elevated $\mathrm{CO} 2$ and warming in a semi-arid grassland. Ecological Applications.

\section{Supporting Information}

Additional Supporting Information may be found in the online version of this article:

Appendix S1 Description of the (a) gap-filling methods employed for the soil water content (SWC), soil temperature (SoilT), photosynthetically active radiation (PAR), air temperature (AirT) and relative humidity (RH) data; (b) linear interpolation of vegetation greenness data.

Appendix S2 Assessment of model performance.

Figures S1(a-e) Time series of the predicted $\log \left(R_{\text {eco }}\right)$ for 2007, 2008, 2010, 2011 and 2012.

Figure S2 Posterior means and 95\% central credible intervals for the antecedent weight parameters.

Figure S3 Correlation between annual $\mathrm{R}_{\mathrm{eco}}$ and precipitation.

Table S1 Posterior means (standard deviations) for parameters in the $R_{\text {eco }}$ mean model (Eqn 2); $\alpha_{0}-\alpha_{8}$ and $\beta_{0}-\beta_{7}$ belong to the temperature sensitivity $\left(E_{o}\right)$ and $\log$ base rate $\left(\log \left(R_{\text {base }}\right)\right)$ functions respectively (Eqns 3 and 4$)$

Table S2 Bayesian $P$-values for each of the 15 pairs of treatment differences for each parameter listed in Table S2a

Table S3 Percentage of data present for the environmental datasets (SWC, SoilT) micrometeorological datasets (PAR, RH, AirT) and the greenness dataset 